\title{
Studies on Neotropical Violaceae 2: Arrangement of Leaves, Inflorescences and Branchlets in Neotropical Rinorea
}

\author{
W. H. A. Hekking \\ Institute of Systematic Botany, Utrecht, The Netherlands
}

\section{Summary}

There exist three different kinds of leaf arrangement in neotropical species of Rinorea.

1. an alternate leaf arrangement consisting of only laminar leaves;

2. an alternate leaf arrangement consisting of laminar leaves in the apical part of the branchlets and scale-like ones subpersistent in the basal part;

3. an apparently opposite leaf arrangement consisting of laminar leaves together with a pair of inconspicuous and soon deciduous scale-like leaves at the base of the inflorescences.

In this article hypotheses have been constructed how one kind of leaf arrangement can be derived from the other, how these three different kinds of leaf arrangements can be correlated with the arrangements of the inflorescences and those of the branchlets, and finally how an apparently opposite leaf arrangement also can be correlated with a so called Fagerlind tree model.

\section{Zusammenfassung}

Es gibt 3 verschiedene Blattstellungen bei neotropischen Arten von Rinorea:

1. eine abwechselnde Blattstellung, bestehend aus nur laubförmigen Blättern

2. eine abwechselnde Blattstellung, bestehend aus laubförmigen Blüttern im oberen Teil der Triebe und aus schuppenförmigen Blättern im unteren Teil der Triebe

3. eine scheinbar gegenständige Blattstellung, bestehend aus laubförmigen Blättern zusammen mit einem Paar von winzigen und fast abfallenden schuppenförmigen Blättern an der Basis der Infloreszenzen.

In diesem Artikel sind Hypothesen formuliert worden, wie man eine bestimmte Art von Blattstellung aus einer anderen ableiten, wie man die 3 verschiedenen Arten von Blattstellungen mit jenen von Infloreszenzen und Trieben verbinden kann und wie man den $Z$ usammenhang zwischen einer scheinbar gegenständigen Blattstellung und einem sogenannten Fagerlindschen Baummodell erkennt.

\section{Introduction}

During my investigation of the different kinds of phyllotaxy and subsequent arrangements of axillary inflorescences and lateral branchlets in Rinorea for a taxonomic Monograph in the Flora Neotropica (Hekking 1988), it appeared that

1. the phyllotaxy of all paleotropical species is alternate

2. only a minority of neotropical species is characterized by an alternate leaf arrangement, while a majority possesses an "apparently opposite" leaf arrangement

3 . in most neotropical species occur two different kind of leaves, laminar and scalelike ones

4. scale-like leaves in most species are inconspicuous and soon deciduous, except in only one species, in which they are subpersistent

5. the occurrence of only laminar leaves is correlated with an alternate leaf arrangement 
6. the occurrence of laminar and subpersistent scale-like leaves is also correlated with an alternate leaf arrangement

7. the occurrence of laminar and deciduous scale-like leaves is correlated with an "apparently opposite" leaf arrangement

8. an "apparently opposite" leaf arrangement is characterized by leaves making an angle of ca. $90^{\circ}$ with each other, instead of an angle of ca. $180^{\circ}$ in "normally opposite" leaves.

The description and explanation of the different kinds of arrangements of leaves, inflorescences and lateral branchlets is so complicated that this special article on this subject is needed in addition to a more summarized one in the Chapter on Morphology in the Monograph of neotropical Rinorea by HekKING (1988).

First of all a historical survey of relevant articles in connection with leaf arrangements is given with some additonal remarks of the present author. Secondarily, a conspectus of a subdivision of neotropical Rinorea into groups, partly based on differences of phyllotaxy is exposed. Subsequently the different kinds of arrangements of leaves, inflorescences and lateral branchlets and the occurrence of two different kinds of leaves are in detail described and discussed in connection with the taxonomic groups in neotropical Rinorea.

Finally, it is also discussed, how both features of two different kind of leaves and a "apparently opposite" leaf arrangement can be derived from a previous character state of only alternate laminar leaves, and how a Fagerlind tree model is correlated with an "apparently opposite" leaf arrangement in the younger branchlets.

\section{History}

Eichler (1870) was the first author who described in detail the occurrence of an "apparently opposite leaf arrangement" in some neotropical species of Rinorea. He concluded, that an alternate leaf arrangement is correlated with a monopodial branching system and that an "apparently opposite" leaf arrangement is correlated with a sympodial branching system. EICHLER also discovered the presence of two deciduous scale-like leaves at the base of the inflorescences of the species with apparently opposite leaves. The conclusions of Eichler have been cited by Troll (1969) in his study on inflorescences. About 100 years after EIchler's publication Oldeman (1974) and HALLÉ et al. (1978) described the branching system of a Rinorea riana tree from a field study in French Guiana. $R$. riana belongs to the group of species with "apparently opposite" leaves. These authors characterized this tree as a "monopodial nonmodular model with indefinite growth of the trunk meristem" in which the lateral branchlets are arranged according to a mono- or dichasial sympodial branching system; they classified such-like structure as the so called "Fagerlind model".

The present author presumed that there would exist a correlation between both hypotheses that of Eichler (1870) and that of OLDEMaN c.s. $(1974,1978)$.

About ten years later, in 1984, WENDT described a new species Rinorea uxpanapana from the Isthmus of Tehuantepec, Mexico, where it occurs on karst limestone of the Uxpana zonation. The taxonomic position of this new species within neotropical Rinorea was problematic because of the possession of two different kinds of alternately arranged leaves viz. laminar and subpersistent scale-like leaves, secondarily by the occurrence of reduced cymose inflorescences (uncommon in neotropical Rinorea) and finally by the slightly zygomorphic character of the flowers. This zygomorphic tendency is expressed by an anterior petal slightly larger than the posterior ones. By these differing characters in inflorescences and flowers, a closer relationship is suggested to some paleotropical species of Rinorea and a more remote relationship to species of the neotropical genus Orthion which has zygomorphic flowers. Therefore, 
the author concluded to place Rinorea uxpanapana in a monospecific group IIb. Uxpanapana (see his Monograph on neotropical Rinorea).

\section{Condensed characterization of neotropical Rinorea}

All species are trees or treelets $2-15(-30) \mathrm{m}$ tall and with a stem $2-20(-50) \mathrm{cm}$ diameter. Most of them occur in the understory of tropical rain- or cloudforests, although some also inhabit gallery-, deciduous or savanna-forests. The altitude of most species varies $0-700 \mathrm{~m}$, but some species even range to the cloud forest zonation of $2,500 \mathrm{~m}$. Their geographical distribution is confined to the tropics of the Old and New World. 48 species occupy an area in neotropical America, extending from Mexico via Brazil and the Guianas to Bolivia and Paraguay; an isolated group occurs in eastern and south eastern coast of Brazil in an area along the Atlantic coast and on the adjacent Plan Alto. The distribution pattern of the genus Rinorea in the neotropics is correlated with the present day areas of the humid forest types, except for the West Indies, where representatives of this genus are wanting.

The inflorescences of neotropical as well as paleotropical species are thyrsoid, pseudoracemose, racemose or cymoid; they occur solitarily or $1-5$ fasciculed in the axils of the leaves. The flowers are arranged in cymules or occur solitarily in the axils of the bracts along the axis of the inflorescence. In pseudoracemose inflorescences cymules with 1-3 flowers as well as solitary flowers can be observed. Solitary flowers can be considered as reduced cymules, since an articulation of the 'pedicels' and a pair of upper bracts (or bractlets) can be considered as an original separation between peduncle and pedicel s. str.

Flowers of Rinorea are predominantly actinomorphic in their structure (Fig. 1). The 5 sepals and petals are free. The sepals are subequal or slightly unequal, the petals are usually equal, sometimes subequal (as e.g. in Rinorea uxpanapana in which the anterior petal is slightly larger than the other ones; the occurrence of a larger anterior petal can be considered as a tendency to a zygomorphic condition of the flower).

The aestivation of the sepals is quincuncial i.e. 2/5 helically arranged with two sepals outside (e), two sepals inside (i) and a fifth sepal partly in-and partly outside (e/i).

The arrangement of the petals is usually different from that of the sepals viz. cochlear (or cochleate), characterized by one petal outside (e), one petal inside (i) and the three other ones partly in- and partly outside (e/i). The cochlear (or cochleate) arrangement in neotropical, and probably also in paleotropical Rinorea is predominantly apotact i.e. the outer petal separated from the inner one by one or two petals partly in- and partly outside. In individual flowers aberrating arrangements may occur viz. a quincuncial arrangement (as in the sepals) as well as a paratact arrangement (characterized by the neighbouring of the outer and the inner petal).

The androecium in Rinorea is composed of 5 episepalous stamens (see diagrams in Fig. 1 A, B, C), each of which consists of a filament, a dorsal gland, an anther, a connective and a dorsal connective scale (c.f. Fig. 1D, E). The structure and the shape of these staminal structures are highly variable in Rinorea. A character state as filaments and dorsal glands completely free can be considered as primitive versus filaments and dorsal glands fused with each other, representing the most advanced stage. The following 3 stages in the structure of the androecium can be distinguished (as expressed in the diagrams of Fig. $1 \mathrm{~A}, \mathrm{~B}, \mathrm{C}$ ):

Stage A: Filaments and dorsal glands completely free; in some species dorsal glands of anterior filaments more developed than those of the posterior ones; dorsal glands of posterior ones sometimes even wanting; by difference in size of the dorsal glands a tendency to zygomorphy is expressed. 
Stage B: Dorsal glands of anterior filaments fused with each other, whereas those of the posterior filament (s) are free; by differences in fusion and size of the dorsal glands a tendency to zygomorphy is expressed.

Stage C: All filaments and usually also all dorsal filaments fused to a tube; this stage can be subdivided mainly by variation in characters of the glandular tissue, which are not treated here (see chapter Morphology in Monograph of Rinorea).

Two different character states of the laminar connective scales on the dorsal side of the anthers in Rinorea can be distinguished (Fig. $1 \mathrm{D}, \mathrm{E}$ ): connective scales exclusively apical as in Supergroup I. Apiculata (Fig. 1D) versus connective scales apical as well as lateral as in Supergroup II. Rinorea. (Fig. 1 E) containing most of the species.

Laminar connective scales apical as well as lateral can be considered as derived from laminar connective scales exclusively apical. In turn laminar connective scales exclusively apical can be considered as derived from connective scales subulate and further from connective scales wanting, if we compare Rinorea with other genera in the Violaceae. The gynoecium is trimerous and the placentation is parietal. Each placenta may contain 1-4 ovules. In the diagrams of Fig. 1 A, B, C, the 3 carpels are differently indicated (open, punctate and hatched); the transverse lines in the center of the carpels indicate the margins of the future valves after dehiscing of the capsule which are composed of two halves of two adjacent carpels. In some species of neotropical Rinorea, the style or stigma is curved to the anterior petal, by which also a tendency to zygomorphy is expressed. This tendency to zygomorphy in the gynoecium may be considered as an advanced character state in comparison to that of a style or stigma erect. The capsule is dehiscing into three valves. The seeds, $1-4$ in each valve, are subglobose or pyriform with an caruncle at the base and an areola at the apex. The seeds are copious with endosperm, in which an erect embryo is enclosed.

\section{Infrageneric Relationships}

Since paleotropical species were excluded from my study, I have refrained from proposing a formal classification in sections and have confined myself to a provisional subdivision of neotropical Rinorea into supergroups and groups, as it is exposed in the Conspectus. Differing character states of connective scales are used to divide neotropical Rinorea into supergroups, whereas differences in inflorescences and leaf arrangements have been used for a more detailed subdivision mainly in groups. In the Monograph of neotropical Rinorea (Flora Neotropica), all groups are subdivided subsequently into subgroups of more or less related species.

Conspectus of the taxonomic groups of neotropical Rinorea.

1. Connective scales exclusively apical; leaves alternate; inflorescences thyrsoid to pseudoracemose.

Supergroup I. 'Apiculata'

1. Connective scales apical as well as lateral; leaves alternate or apparently opposite; all kinds of inflorescences.

Supergroup II. 'Rinorea'

2. Inflorescences cymose, without a distinct central axis, subsessile; two different kinds of leaves distinctly present; apical leaves laminar and petiolate; basal leaves scale-like, sessile, persistent; both kinds of leaves alternate.

Group IIb. 'Uxpanapana'

2. Inflorescences thyrsoid, pseudoracemose or racemose, always with a distinct central axis; only one kind of leaves i.e. laminar leaves distinctly present; scale-like leaves inconspicuous and soon deciduous or wanting. 
3. Leaves alternate; scale-like leaves usually wanting (if occasionally present minuscule and inconspicuous). Group II a. 'Rinorea'

3. Leaves apparently opposite (in R.hymenosepala apical laminar leaves apparently opposite, basal leaves alternate); laminar leaves distinctly present; scale-like leaves inconspicuous, inserted at the base of each inflorescence, soon deciduous.

Group II c. 'Pubiflora'

From more detailed morphological studies it appeared that three different kinds of arrangements of leaves, inflorescences and branchlets in neotropical Rinorea can be distinguished, as follows:

a) leaves alternate; leaves usually only laminar and petiolate; scale-like leaves usually wanting, if occasionally present minuscule and inconspicuous; inflorescences in the axils of subtending laminar leaves and provided with a distinct central axis; branchlets predominantly monopodial (Figs. 2, 3, 4).

This arrangement occurs in all paleotropical and in those of some neotropical groups viz. Supergroup I. Apiculata and Group IIa. Rinorea. Both groups include a minority of the total number of the neotropical species.

b) leaves alternate; two different kinds of leaves; petiolate laminar leaves in the apical part of the branchlets and sessile scale-like leaves in the basal part of the branchlets; scale-like leaves persistent and accompanied with two scale-like stipules; inflorescences $1-3$ fasciculate in the axils of and subtended by both kinds of leaves; cymules with $1-3$ flowers and (nearly) without peduncle; branchlets predominantly sympodial, sometimes also monopodial (Figs. 6, 7).

This arrangement is restricted to only one species Rinorea uxpanapana, which is therefore placed in a separate Group II b. Uxpanapana. This species is endemic in Mexico.

c) leaves apparently opposite, i.e. making an angle of ca. $90^{\circ}$ with each other (versus ca. $180^{\circ}$ in genuinely opposite leaves); two different kinds of leaf pairs, either consisting of petiolate laminar leaves or of sessile scale-like leaves; scale-like leaves not accompanied by stipules and soon deciduous; both kinds of leaf pairs occurring together on a fused single nodular structure at the apex of the branchlets; inflorescences solitary in the axils of subtending scale-like leaves, seeming also inserted in the axils of laminar leaves but in reality making an angle of ca. $90^{\circ}$ with the latter; inflorescences provided with a distinct central axis; lateral branchlets solitary in the axils of subtending laminar leaves; branching system sympodial, either monochasial in case of one (series of) lateral branchlet(s) or dichasial in case of two (series of) lateral branchlets (Figs. 8-17).

This complicated arrangement of leaves, inflorescences and lateral branchlets occurs only in the neotropical Group IIc. Pubiflora, which includes the majority of the species in the neotropics.

The leaves (and likewise the axillary inflorescences) of the species of Supergroup I. Apiculata and those of Group IIa. Rinorea are spirally arranged probably also according to $2 / 5$ arrangement, just as in the quincuncial aestivation of the sepals in the flowers. In Fig. 2 two series of growing-processes in apical branchlets of species with alternate leaves have been reconstructed from herbarium material. Results of structural analyses have been combined in more schematic drawings of Fig. 3. The signification of the symbols on both figures are similar so that they easily can be compared with each other. In Fig. $2(\mathrm{I}-\mathrm{V})$ and Fig. 3 (I) we see a vertical axis CA $\left(\mathrm{CA}^{\prime}, \mathrm{CA}^{\prime \prime}\right)$ bearing alterna telyarranged laminar leaves $\mathrm{L}_{1}, \mathrm{~L}_{2}$ and $\mathrm{L}_{3}$, accompanied by a pair of stipules (st, st') and subtending respective lateral buds $L B_{1}, L_{2}$ and $\mathrm{LB}_{3}$, which may give rise to new lateral branchlets (also indicated as $\mathrm{LB}_{1}, \mathrm{LB}_{2}$ and 
$\left.\mathrm{LB}_{3}\right)$. The stipules $\left(=\right.$ st' $^{\prime}$ ) of apical laminar leaf $\mathbf{L}_{3}(\mathrm{Fig} .2, \mathrm{IV}-\mathrm{V}$ ) enclose an apical vegetative bud $A B$ as well as its own lateral bud $L B_{3}$. The apical bud $A B$ and eventually also the lateral buds $\mathrm{LB}_{1-3}$ may give rise to branchlets of a younger generation, starting with a pair of prophylls $x$ and $\beta$ (see AB in Fig. 2) (II and IV). This pair of prophylls encloses the stipules and laminar leaves of the next generation $\left(\mathrm{L}_{1}^{\prime}, \mathrm{L}_{2}\right.$, st"). Stipules and prophylls are soon deciduous.

In Fig. 3(I) laminar leaves $L_{1}, L_{2}$ and $L_{3}$ also are subtending inflorescences $\left(=I F_{1}\right.$, $\mathrm{IF}_{3}$ and $\mathrm{IF}_{3}{ }^{\prime} ; \mathrm{IF}_{3}{ }^{\prime}$ is a lateral inflorescence associated with the central one $\mathrm{IF}_{3}$ ). The central axis of this thyrsoid inflorescence starts with three or more prophylls, indicated here as $\alpha, \beta$ and $\gamma$. All laminar leaves are accompanied by a pair of two deciduous stipules $(=$ st); scale-like leaves are wanting.

In Fig. 3 (II), we see again a central axis CA with an apical vegetative bud AB and with 6 alternate laminar leaves $\mathrm{L}_{1-6}$, subtending respectively the lateral buds $\mathbf{L B}_{1,3-6}$, one lateral branchlet $\mathbf{L B}_{2}=\mathrm{CA}^{\prime}$ and inflorescences $\mathrm{IF}_{4}, \mathrm{IF}_{4}{ }^{\prime}$ and $\mathrm{IF}_{5}$ (just as in preceding analytical drawings in Figs. 2 and 3). The lateral branchlet $\mathbf{L B}_{2}$ becomes to a secondary central axis $\mathrm{CA}^{\prime}$, which can be subdivided into 3 parts:

a) hyp. = hypopodium $=$ internodium between the subtending leaf $L_{2}$ and prophyll $x$;

b) mes. $=$ mesopodium $=$ internodium between the prophylls $\alpha$ and $\beta$;

c) ep. = epipodium $=$ apical part of $\mathrm{LB}_{2}=\mathrm{CA}^{\prime}$, bearing the laminar leaves $\mathrm{L}_{1}^{\prime}$, $\mathrm{L}_{2}^{\prime}$ and $\mathrm{L}_{3}{ }^{\prime}$.

The significations of other symbols in this lateral branchlet have been explained above. The internodia of the epipodia become more elongated than those of the mesoand the hypopodium. In most species the internodia of the epipodium are more or less equally long, except in three closely related species: Rinorea maximiliani, $R$. laevigata and $R$. ramiziana (Fig. 4 [II and III]). In those species the basal internodia of the epipodium are more elongated than the apical (= distal) ones, so that leaves, axillary inflorescences and younger lateral branchlets often are congested on nodular structures at the apices of (older) branchlets. It seems that apical buds stop to grow or become obliterated periodically. In the later case lateral buds may give rise to a new generation of lateral branchlets, of which one may take over the function as a secondary central axis. This periodical growth may be influenced by the local climate in SE Brazil, which probably has reiterated dryer and more humid periods. Subsequently a monopodial branching system often becomes changed into a sympodial one, when some lateral branching systems take over the function as secondary central axes.

On some herbarium specimens of $R$. laeviguta (e.g. SuCRE 1537) minuscule scalelike leaves have been found in the basal part of the epipodium of younger branchlets (Fig. 5 (I)). These scale-like leaves $\left(l_{1}=v_{1} ; l_{2}=v_{2}\right)$ are accompanied by a pair of stipules (= st) and are subtending an inactive lateral bud (respectively $\mathbf{L B}_{1}$ and $\mathbf{L B}_{2}$ ). Some of them are still differentiated into a reduced petiole and a reduced lamina (Fig. 5. (II)).

Such scale-like leaves are more conspicous in $R$. uxpanapana, belonging to the next group IIb. Uxpanapana (Figs. 6, 7).

The leaves of Rinorea uxpanapana, the only species of Group IIb. Uxpanapana, are spirally arranged, probably according to $2 / 5$ arrangement, just as the species in Supergroup I. Apiculata and those of Group IIa. Rinorea. There occur two different kinds of leaves in $R$. uxpanapana (Figs. 6, 7); petiolate laminar leaves (L. etc.) in the apical part of the epipodium of the branchlets and sessile-scale like leaves $(l=v$, etc.) in the basal parts. Both kinds of leaves are accompanied by a pair of sub- 
persistent stipules (st); the stipules are more or less similar in shape and in habit as the sessile scale-like leaves. Inflorescences (IF etc.) consist of cymules with $1-3$ flowers (nearly) without peduncle; they occur $1-3$ fasciculate in the axils of both kinds of leaves, laminar as well as scale-like. Some of the scale-like leaves (cf. Fig. 6 (I and $I V)$ ) are still differentiated into a reduced petiole and a reduced lamina. Therefore it is most likely, that the character state of scale-like can be derived from that of laminar leaf. In the next group IIc. Pubiflora, the character state of the scale-like leaves is still more derived, since the scale-like leaves have become inconspicuous, soon deciduous and deprived from their stipuless (see below). Ontogenetically scale-like leaves share the same origin as the laminar leaves, but the differentiation remained secondarily backward in scale-like leaves. It is also striking, that laminar leaves of $R$. uxpanapana are deciduous. Their petioles are articulate at the base, so that they can easily be dropped by abcission, when the seasonal circumstances are unfavourable. This character is unique in neotropical Rinorea. The species $R$. uxpanapana occurs on karst limestone of the Uxpanapa zonation on the Isthmus of Tehuantepec, Mexico and is probably endemic there (WENDT in litt., 1983). The species is probably limited in its distribution not only geographically but also ecologically. The study of its ecology and physiology will be continued by WeNDT and his collaborators, who discovered this interesting species.

The arrangement of the two different kinds of leaves as usually in $R$. uxpanapana is more or less similar as ocasionally in R. laevigata (compare Fig. 6 with Fig. 5). Its branching system is also predominantly sympodial by periodical growth, as it appears from the facts that 1 . the apical (= distal) laminar leaves are more closely inserted than the lower ones; 2 . the apical vegetative bud at the apex of the branchlets stops periodically growing ( $*$ in Fig. 7), and 3. the lateral buds give rise to newly formed lateral branchlets (LB etc. in Figs. 6 and 7 ; prophylls $\alpha$ and $\beta$ have not been indicated since they are not clearly distinguished from the scarious scale-like leaves and their accompanying stipules (in herbarium specimens)). In older branchlets the sympodial appearance have faded away and is only visible as a slight curve at the base of the branchlets, which became secondarily to a new central axis $\left(\mathrm{LB}_{1}=\mathrm{CA}^{\prime}\right.$ in Fig. 7 (I and II)). Usually one or two lateral branchlets (Fig. 7) have been formed respectively, resulting in a mono- or dichasial branching system. Sometimes also 3 lateral branchlets are growing from the apex of an older branchlet. Such-like arrangement may result either from growing of 3 younger lateral branchlets $L B_{1}, L_{3}$ and $L_{3}$ (in Fig. 6) after self-eliminating of the central (formerly apical) vegetative bud ( $*$ in Fig. 7 (II)) or from continued growth of the original central axis CA accompanied by growing of two younger lateral branchlets (e.g. combination of $C A, L B_{2}$ and $L_{3} B_{3}$; this alternative arrangement has not been illustrated here).

The species of group IIc. Pubiflora are characterized by the occurrence of a pair of apparently opposite laminar leaves at the apex of the branchlets (Figs. 8 and 9). After a further analysis, also a pair of scale-like leaves can be seen at (or better just below) the base of the inflorescence; these scale-like leaves are inconspicuous and soon deciduous; accompanying stipules are wanting. The apical branchlets bear also two prophylls $\alpha$ and $\beta$ in the basal part; they are soon decidous. The structure of these branchlets can be compared with that of the lateral branchlets of species with alternate leaves, belonging to group II a. Rinorea (Figs. 3 (II), 5 (I). 10 (III), 11-13). The branchlet structure in group II c. Pubiflora also can be subdivided into a hypopodium (= internodium between the subtending leaf and prophyll $\alpha$ ), a mesopodium (= internodium between prophylls $\alpha$ and $\beta$ ) and finally an epipodium, bearing the leaves of both different kinds at its apex; in group IIc. Pubiflora only the basal part of the epipodium becomes distinctly more elongated than the other parts in the branchlets. 
The structure of the apical branchlets of the species with apparently opposite leaves, belonging to group II c. Pubiflora, has been become more complicated by the following processes:

a) fusion of the nodes, bearing the leaves, with each other to a single nodular structure, resulting in two pairs of subopposite leaves close together on this new structure (Figs. 9-13);

b) a stimultaneous alterion of one of the two pairs of laminar leaves into a scale-like contidion (Figs. 9-13);

c) a repeated self-eliminating of the succesive apical vegetative buds, which provoke lateral buds in the axils of subtending leaves to give rise to lateral branchlets, which take over the function of central axis from the previous one (Figs. 8-15).

This complicate apparently opposite position of the leaves in the species of Group II c. Pubiflora can be derived from a previous alternate phyllotaxy as occurs in the species of Group II a. Rinorea, as follows:

1. After the self-eliminating of the apical vegetative bud (*) at the apex of the central axis CA, further growth of the branching systems will by taken over by lateral bud $\mathrm{LB}_{0}$, and later on probably also by lateral bud $\mathrm{LB}_{1}$, occurring in the axils of the respective subtending leaves $L_{0}$ and $L_{1}$. Both subtending leaves ar inserted on nodes along the epipodium of central axis CA (Fig. 10 (I)); they are alternately arranged, making an angle of ca. $180^{\circ}$ with each other.

2. The lateral bud $\mathrm{LB}_{0}$ in the axil of subtending leaf $\mathrm{L}_{0}$ gives rise to a short lateral branchlet $L B_{0}$, which bears also two alternately arranged leaves $l_{0}$ and $l_{1}$, also making an angle of ca. $180^{\circ}$ with each other; $l_{0}$ is a subtending leaf of inflorescence IF (Fig. $10(\mathrm{I})$ and Fig. 16 (Diagram I)). ${ }^{1}$ )

3. If we compare the alternate leaf arrangement in the lateral branchlet $L_{1} B_{0}$ with that of the central axis CA, it appears that both make an angle of ca. $90^{\circ}$ with each other; this means that leaf $\mathrm{l}_{0}$ of $\mathrm{LB}_{0}$ makes an angle of ca. $90^{\circ}$ with its equivalent $L_{0}$ of CA and like wise do $l_{1}$ and $L_{1}$ (Fig. 10 (I) and Fig. 16 (Diagram III)).

4. When subsequently, the two nodes of lateral branchlet $\mathrm{LB}_{0}$, bearing the leaves $l_{0}$ and $l_{1}$ become fused with the two nodes of central axis $\mathrm{CA}$, bearing the leaves $\mathrm{L}_{0}$ and $\mathrm{L}_{1}$, the 4 leaves become inserted together on a single nodular structure at the apex of the CA (this means also that lateral branchlet $\mathrm{LB}_{\mathbf{0}}$ is fused with the apical part of the epipodium of central axis CA) (Fig. 10 (II and III)).

5. Subsequently, the lowermost leaves of $C A$ and $\mathrm{LB}_{0}$ become suppressed in their outgrowth and remain scale-like (viz. respectively $\mathrm{L}_{0}=\mathrm{N}$ and $\mathrm{l}_{0}=\mathrm{v}$; the latter is the subtending leaf of inflorescence IF). However, the two uppermost leaves of $C A$ and $L_{B}$ remain laminar (viz. $L_{1}$ and $l_{1}$, subtending lateral buds, which may give rise later on to other new lateral branchlets $L B_{1}$ and $\left.L B_{2}\right)($ Figs. 10 , 16); leaves becoming scale-like are indicated open; leaves remaining laminar are indicated hatched in the illustrations of Figs. 8-15 and black in the diagrams of Figs. 16, 17. Since the phyllotaxy of these 4 leaves remain unmodified after the fusion of their nodes to the single nodular structure, the scale-like leaves $\mathrm{N}$ and $v$ still make an angle of ca. $90^{\circ}$ with each other and likewise $L_{1}$ and $l_{1}$. The two scale-like leaves (or their scars) are still visible just below the base of the inflorescence. The inflorescence IF seems to be also inserted in the axil of laminar leaf $L_{1}$, but in reality it also makes an angle of ca. $90^{\circ}$ with that laminar leaf, since its subtending scale-like leaf $l_{0}=v$ does likewise (Fig. 10 (III); Fig. 16 (diagram III)).

1) Some details of Fig. 16 after Erchler (1870 t. 4) and Troll (1966 fig. 435) but modified. 
6. Since the apical vegetative buds of $\mathrm{CA}$ and $\mathrm{LB}_{0}$ become self-eliminating (*) their function will be taken over by the younger lateral buds $L_{B}$ and/or $L B_{2}$, inserted in the axils of their respective subtending leaves $L_{1}$ and $l_{1}$. If lateral bud $L_{1}$ or $L_{2}$ will give rise to a new generation of lateral branchlets, this will result in a monochasial branching system; if both lateral buds give rise to a new generation of lateral branchlets, this will result in a dichasial branching system (Figs. 10-15).

In a dichasial system, lateral branchlets $L B_{1}$ and $L B_{2}$ will make an angle of ca. $90^{\circ}$ with each other, while their subtending leaves $L_{1}$ and $l_{1}$ do likewise (Figs. 13 (V), 14 (V), 15 (VIII), 16 (diagram V), 17 (diagram $V^{\prime}$ ).

7. In a monochasial system a new lateral branchlet $\mathrm{LB}_{1}$ (or $\mathrm{LB}_{2}$ ) takes the function over as a new central axis $\mathrm{CA}^{\prime}$ from the previous one $\mathrm{CA}$. The whole procedure of arrangement of the prophylls, leaves, inflorescences and lateral branchlets as exposed already for $\mathrm{CA}$, is similar for $\mathrm{CA}^{\prime}$ (in which all the symbols are provided with an accent). However the whole arrangement in $\mathrm{CA}^{\prime}$ makes an angle of ca. $90^{\circ}$ with that of CA (Fig. 10 (IV a); Fig. 16 (Diagram IV a)).

8. The basal part of $\mathrm{LB}_{1}$ (or $\mathrm{LB}_{2}$ ) $=\mathrm{CA}^{\prime}$, consisting of the hypopodium and the mesopodium and bearing the two prophylls $\alpha$ and $\beta$, remains backward in elongation. Therefore the two prophylls $\alpha$ and $\beta$ remain at the base of $\mathrm{LB}_{1}$ (or $\mathrm{LB}_{2}$ ) $=\mathrm{CA}^{\prime}$ farly separated from the leaves on the nodular structure at the apex; the two prophylls $\alpha$ and $\beta$, making an angle of ca. $180^{\circ}$ with each other and in predisposition alternate, become secondarily subopposite (Figs. 10 (IVa), 11-12. 16 (diagrams IV a and IV b)).

9. In a continuing monochasial system, homologous laminar leaves $\mathrm{L}_{1}, \mathrm{~L}_{1}^{\prime}, \mathrm{L}_{\mathbf{1}}{ }^{\prime}$, $L_{1}^{\prime \prime \prime}$ etc. make an angle of ca. $90^{\circ}$ with each other and likewise the homologous laminar leaves $l_{1}, l_{1}^{\prime}, l_{1}{ }^{\prime \prime}, l_{1}^{\prime \prime \prime}$ etc. Not-homologous leaves $L_{1}, l_{1}^{\prime}, L_{1}{ }^{\prime \prime}, l_{1}^{\prime \prime \prime}$ etc. are arranged parallel above each other and make an angle of ca. $90^{\circ}$ with another series of not-homologous leaves $\mathrm{l}_{1}, \mathrm{~L}_{1}{ }^{\prime}, \mathrm{l}_{1}{ }^{\prime \prime}, \mathrm{L}_{1}{ }^{\prime \prime}$ etc., in turn also arranged parallel above each other. This results in two series of parallel not-homologous laminar leaves and two series of alternately arranged homologous laminar leaves as follows:
$\mathrm{l}_{1}{ }^{\prime \prime \prime}-\mathrm{L}_{1}^{\prime \prime \prime}$ (apparently opposite with a ca. $90^{\circ}$ angle)
$\mathbf{L}_{1}^{\prime \prime}-\mathbf{l}_{1}^{\prime \prime}$
$\mathrm{l}_{1}{ }^{\prime}-\mathrm{L}_{1}{ }^{\prime}$
$\mathrm{L}_{1}-\mathrm{l}_{1}$
(idem)
(idem)
(idem)

10. In a continuing monochasial system, homologous scale-like leaves $\mathrm{L}_{0}, \mathrm{~L}_{0}{ }^{\prime}, \mathrm{L}_{0}{ }^{\prime \prime}$, $\mathrm{L}_{0}{ }^{\prime \prime \prime}$ etc. ( $=\mathrm{N}, \mathrm{N}^{\prime}, \mathrm{N}^{\prime \prime}, \mathrm{N}^{\prime \prime \prime}$ etc.) make an angle of ca. $90^{\circ}$ with each other and likewise the homologous scale-like leaves $1_{0}, \mathrm{l}_{0}{ }^{\prime}, \mathrm{l}_{0}{ }^{\prime \prime}, \mathrm{l}_{0}{ }^{\prime \prime \prime}$ etc. $\left(=\nabla, \mathrm{v}^{\prime}, \mathrm{v}^{\prime \prime}, \mathrm{v}^{\prime \prime \prime}\right.$ etc.). Not-homologous scale-like leaves $N, \mathbf{v}^{\prime}, \mathrm{N}^{\prime \prime}, \mathbf{v}^{\prime \prime \prime}$ etc. are arranged parallel above each other and make an angle of ca. $90^{\circ}$ with another series of not-homologous scale-like leaves $\mathrm{v}, \mathrm{N}^{\prime}, \mathrm{v}^{\prime \prime}, \mathrm{N}^{\prime \prime \prime}$ etc., in turn also arranged parallel above each other. This results in two series of parallel not-homologous scale-like leaves and two series of alternately arranged homologous scale-like leaves as follows:

$\begin{array}{cc}\mathbf{v}^{\prime \prime \prime}-\mathbf{N}^{\prime \prime \prime} & \text { (apparently opposite with a ca. } 90^{\circ} \text { angle) } \\ \mathbf{N}^{\prime \prime}-\mathbf{v}^{\prime \prime} & \text { (idem) } \\ \mathbf{v}^{\prime}-\mathbf{N}^{\prime} & \text { (idem) } \\ \mathbf{N}-\mathbf{v} & \text { (idem) }\end{array}$

These alternation patterns have been reconstructed in the diagrams of Figs. 16 and 17; they also explain the occurrence of both a 'clockwise' position of the scale-like leaves $\left(\mathbf{N}-\mathbf{v}, \mathbf{N}^{\prime \prime}-\mathbf{v}^{\prime \prime}\right)$ and a 'anti-clockwise' $\left(\mathbf{v}^{\prime}-\mathbf{N}^{\prime}, \mathbf{v}^{\prime \prime}-\mathbf{N}^{\prime \prime \prime}\right)$ position at the base of the inflorescences, still visible on herbarium specimens (Fig. 9 ). 
All the following generations of inflorescences IF, IF', IF", IF"' etc. are inserted in the axils of a series of substending scale-like leaves $\mathbf{v}, \mathrm{v}^{\prime}, \mathrm{v}^{\prime \prime}, \mathrm{v}^{\prime \prime \prime}$ etc. The same series of inflorescences seem to be inserted in the axils of laminar leaves $\mathrm{L}_{1}, \mathrm{~L}_{1}{ }^{\prime}$, $\mathrm{L}_{1}{ }^{\prime \prime}, \mathrm{L}_{1}^{\prime \prime \prime}$ etc. (which are also alternating with each other), but in reality the inflorescences make an angle of ca. $90^{\circ}$ with them just like their subtending scalelike leaves $v, \mathbf{v}^{\prime}, \mathbf{v}^{\prime \prime}, \mathbf{v}^{\prime \prime \prime}$ etc. (see also under 5).

11. In a continuing monochasial system, a similar series can be reconstructed for the respective prophylls $\alpha$ and $\beta$, as it is demonstrated in the diagrams of Figs. 16 and 17.

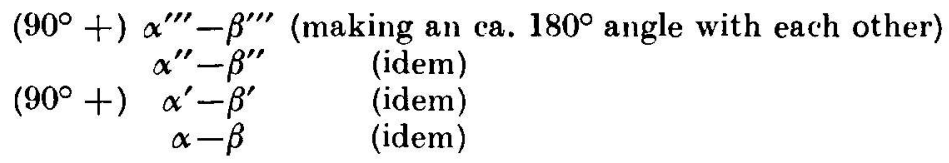

In this way there are two series of prophylls which are arranged exactly parallel above each other ( $\alpha$ and $\beta, \alpha^{\prime \prime}$ and $\beta^{\prime \prime}$ etc.) and ( $\alpha^{\prime}$ and $\beta^{\prime}, \alpha^{\prime \prime \prime}$ and $\beta^{\prime \prime \prime}$ etc.), both making an angle of ca. $90^{\circ}$ with each other.

12. The reiterated leaf arrangement can be expressed by the following formula:

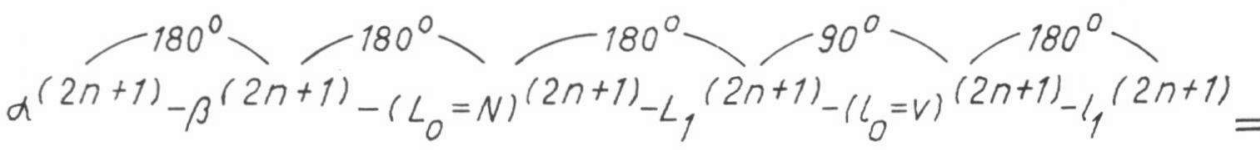

$$
\begin{aligned}
& 90^{\circ}+\left[\alpha^{2 n}-\beta^{2 n}-\left(L_{0}=N\right)^{2 n-L_{1} 2 n-\left(l_{0}=v\right)^{\left.2 n-l_{1} 2 n\right]}}\right.
\end{aligned}
$$

13. If lateral bud $L B_{2}$ gives rise to a lateral branchlet $L B_{2}$ instead of $L B_{1}$, this also results in a monochasial branching system, however starting in the axil of subtending laminar leaf $\mathrm{l}_{1}$ (apparently opposite of the other laminar leaf, subtending lateral bud $\mathrm{LB}_{1}$ ). Both continuing monochasial branching systems, the $\mathrm{LB}_{1}$ and the $\mathrm{LB}_{2}$ system have both a slightly different origin, as it is depicted in Fig. $11\left(\mathrm{IV}_{\mathrm{a}}{ }^{\prime}\right)$ and Fig. 17 (diagram $I V_{\mathrm{a}}{ }^{\prime}$ ) for the $L B_{1}$ system and in Fig. $12\left(I V_{b}{ }^{\prime}\right)$ and Fig. 17 (diagram $I V_{b}{ }^{\prime}$ ) for the $L B_{2}$ system. The final results of both lateral branching systems are similar and the original differences of both systems are no more visible on herbarium specimens.

14. If, however, both lateral buds $L B_{1}$ and $L_{2}$ give rise to a new generation of lateral branching systems $L B_{1}$ and $L B_{2}$ a dichasial system is started (Figs. $13(\mathrm{~V})$, $14(V), 16$ (diagram V), 17 (diagram $V^{\prime}$ ). In diagrams IV a and IVb of Fig. 16 and $I V^{\prime} a^{\prime}, I V b^{\prime}$, and $V$ of Fig. $17 \mathrm{I}$ concluded to a different leaf arrangement in the more complicated situation as depicted in Fig. 434 of Troll 1969, since Troll did not follow consequently the leaf arrangement as formulated under 9.

15. Rinorea hymenosepala is the only species of Group IIc. Pubiflora, in which the apical leaves are apparently opposite, whereas the basal ones are still alternate as in the species of Group II a. Rinorea. This fact supports the hypothesis, that an apparently opposite leaf arrangement indeed can be derived from an alternate one. $R$. hymenosepala is closely related to $R$. ulmifolia, in which all laminar leaves are apparently subopposite. 
16. In Fig. 15 (VIII), a transection of a stem of a Rinorea species with apparently opposite leaves, belonging to group IIc. Pubiflora, is given. This stem bears on this transection a tire of three plagiotropic flowering branchlets, $L B_{1}, L_{2}$ and $\mathrm{LB}_{3}$ (symbols not necessarily convening with those used above). These branches have a mixed mono- and dichasial sympodial pattern of horizontally arranged branchlets. The laminae of the apparently opposite leaves along these branchlets also became horizontally arranged.

This horizontal sympodial arrangement of branches and the branchlets in combination with that of the laminar leaves is most efficient for catching as much light as possible. Most of the species of Rinorea, as already mentioned above, are treelets confined to the understory of the tropical rain forests, which receives only the minute part of the daylight, that passes the canopy. White spike-like inflorescences rise, slantingly erect from the branchlets like candles, luring pollinating insects by means of their fragrant odour coming from their nectaries (i.e. the dorsal glands of the filaments or the fused filamentar tubes).

17. Mono- and dichasial branching systems as described above occur only in horizontally arranged branches and branchlets. If, however, the central axis CA is vertically directed (Fig. 14 (IV)), the situation becomes modified as follows:

a) After the self-elimination of the vegetative bud (*) at the apex of central axis CA, a similar fusion of nodes and internodes also results in a single nodular structure as in a horizontal monochasial branching system, but without a, reduction of laminar to scale-like leaves. In this way all the leaves $L_{0}, l_{0}$ $\mathrm{L}_{1}$ and $\mathrm{l}_{1}$ remain laminar.

b) Because of self-elimination of the terminal vegetative bud of CA, all axillary buds may give rise to a next generation of lateral branchlets $L_{1}, L_{1} B_{2}, L_{3}$ and $\mathrm{LB}_{4}$. Sometimes one or more lateral branchlets is/are replaced by an inflorescence or one or more of the lateral buds remain dormant.

Such nodular structures on which laminar leaves are secondarily ternate or quaternate can be found in nearly all species of Group II c. Publiflora. ${ }^{1}$ )

18. The function of the previous central axis CA is often taken over by one of the lateral branchlets which becomes, secondarily, a newly formed central axis $\mathrm{CA}^{\prime}$ (Fig. $15(\mathrm{IX})$ ), while the other three remain lateral branches $\left(\mathrm{LB}_{1}, \mathrm{LB}_{2}\right.$, and $\mathrm{LB}_{3}$ in Fig. 15 (VIII)). This results in an unstably monopodial structure of the treelet, which often or periodically gives rise to sympodial branchings. OLdemaN (1974) and HALLÉ et al. (1978) described this structure from a treelet of $R$. riana from French Guiana. Personally, I saw such structures also in other species as $R$. macrocarpa (Colombia), R.pubiflora (Surinam) and R. viridifolia (Colombia). I believe, that such structures are common in all species of Group II c. Pubiflora. HALLÉ et al. (1978) characterized such trees and treelets as a "monopodial nonmodular model with indefinite growth of the trunk meristem" and classified their structure as the so-called Fagerlind model ${ }^{1}$ ).

Conclusion: Since a Fagerlind tree model can be correlated with an apparently opposite leaf arrangement in the branchlets and since this leaf arrangement can be

1) Similar nodular structures also can be observed in some species with alternately arranged leaves as in the three closely related species Rinorea maximiliani, $R$. laevigata and $R$. ramiziana of Group IIa. Rinorea (Fig. 4 (II and III) and occasionally also in $R$. crenata of Supergroup I. Apiculata (Fig. 4 (I)). We presume that these nodular structures of these species are formed on more or less vertically oriented branching systems.

1) The illustrations of Fig. 15 (VIII, IX) are taken from OLdemax (1974) and from HaLLÉ et al. (1978), however in a slightly modified way. 
derived from an alternate one, I conclude that also a Fagerlind tree model can be derived from the one belonging to the species with alternate leaves; alas a tree model belonging to the species with alternate leaves has not yet studied in vivo.

\section{Acknowledgements}

The author wishes to express his gratitude to Professor Dr. A. L. Stoffers under whose directorship the present study was carried out. Thanks are also due to Prof. Dr. F. WEBERLING for reading the manuscript and for giving advice.

General Legend of the Illustrations made by the Author (Fig. 1-17)
$\alpha$ and $\beta ; \alpha^{\prime}$ and $\beta^{\prime} \quad=$ prophylls at the base of young (lateral) branchlets $(=$ LB etc.) (Figs. 2-17);
$\alpha, \beta$ and $\gamma \quad=$ prophylls at the buse of inflorescences (= IF etc.) (Figs. 3, 4 and 9);
$\mathrm{AB}, \mathrm{AB}^{\prime} \quad=$ apical bud (Figs. 2-3);
B = bracts at the base of the 'pedicels' along the central axis of the in- florescences (IF etc.) (Figs. 4 and 9);
b . = bractlets just below the articulations of the 'pedicels' (Figs. 4 and 9);
CA (CA', CA" etc.) = central axis (Secondary central axes) (Figs. 2-17);
E $\quad=$ terminal flowers of inflorescences (= IF etc.) (Figs. 3 and 4);
$\theta(=$ exterior $) \quad=$ outer sepal or petal (Fig. 1);
$\mathrm{e} / \mathrm{i}$ (= exterior; $\mathrm{i}=$ interior)
$=$ sepal or petal with one margin outside and the other margin inside (Fig. 1);
ep. $\quad=$ epipodium, part of branchlets above the prophylls $\alpha$ and $\beta$ (Figs. 3, 5, 10-13);
FL $\quad=$ flower(bud) (Fig. 9);
hyp. $\quad=$ hypopodium, part of branchlets below the prophylls $\alpha$ and $\beta$ (Figs. 3,5, $10-13)$;
$\mathrm{i}(=$ interior $) \quad=$ inner sepal or petal (Fig. 1);

i/e (i = interior; $\theta=$ exterior)

$=$ sepal or petal with one margin inside and the other margin outside (Fig. 1);

IF (IF', IF" etc.; IF $, \mathrm{IF}_{1}, \mathrm{IF}_{2}$ etc. or combinations)

$=$ inflorescences (Figs. 2-17);

$\mathbf{L}\left(\mathbf{L}_{0}, \mathbf{L}_{1}, \mathbf{L}_{2}\right.$ etc.; $\mathbf{L}^{\prime}, \mathbf{L}^{\prime \prime}, \mathbf{L}^{\prime \prime \prime}$ etc. and combinations) (hatched)

$=$ laminar leaves (Figs. 2-17);

$\mathrm{L}_{0}\left(\mathrm{~L}_{0}^{\prime}, \mathrm{L}_{0}^{\prime \prime}, \mathrm{L}_{0}{ }^{\prime \prime \prime}\right.$ etc.) (open)

$=\mathbf{N}\left(\mathbf{N}^{\prime}, \mathbf{N}^{\prime \prime}, \mathbf{N}^{\prime \prime \prime}\right)=$ (scars of) scale-like leaves (Fig. 8-17);

[ $\left.\mathrm{L}_{7}\right]=$ laminar leaf $\mathrm{L}_{7}$ broken off (Fig. 6);

$1\left(l_{1}, l_{2}, l_{3}\right.$ etc.; $l^{\prime}, l^{\prime \prime}, l^{\prime \prime \prime}$ etc. and combinations) (hatched)

$=$ laminar leaves (Figs. 8-17);

$l\left(l_{0}, l_{1}, l_{2}\right.$ etc.; $l^{\prime}, l^{\prime \prime}, l^{\prime \prime \prime}$ etc. and combinations) (open)

$=\mathrm{v}\left(\mathrm{v}_{0}, \mathrm{v}_{1}, \mathrm{v}_{2}\right.$ etc.; $\mathrm{v}^{\prime}, \mathrm{v}^{\prime \prime}, \mathrm{v}^{\prime \prime \prime}$ etc. and combinations)

$=$ (scars of) scale-like leaves (Figs. 5-17); 
$=$ juvenile laminar leaf $l_{1}$ of $L_{B} B_{0}$ enclosed by its stipules (= st) (Fig. 8)

$\mathrm{LB}\left(\mathrm{LB}_{1}, \mathrm{LB}_{2}\right.$ etc.; $\mathrm{LB}^{\prime}, \mathbf{L B}^{\prime \prime}$ etc. and combinations)

= lateral buds or lateral branchlets (Figs. 2-17);

$\mathrm{LB}_{0}$

= lateral branchlet of Rinorea laevigata, containing lateral buds $\mathbf{L B}_{1}$, $\mathrm{LB}_{2}, \mathrm{LB}_{3}$ and $\mathrm{LB}_{4}$ of a younger generation (Fig. 5); lateral branchlet of trunk in Fagerlind model, becoming to a secondary central axis $\mathrm{CA}^{\prime}$ (Fig. 15 (IX)).

$\mathbf{L B}_{\mathbf{0}}\left(\mathrm{LB}_{\mathbf{0}}{ }^{\prime} \cdot \mathbf{L B}_{\mathbf{0}}{ }^{\prime \prime}\right.$ etc.) = lateral bud enclosing or lateral branchlet reduced to a nodular struct ure containing scale-like leaf $l_{0}=v$ (open), laminar leaf $l_{1}$ (hatched) and inflorescence IF (IF', IF" etc.) (Figs. 8-13 and 16-17);

mes.

$=$ mesopodium, part of the (lateral) branchlets between the prophylls $\alpha$ and $\beta$ (Figs. 3, 5, 10-13);

$\mathbf{N}\left(\mathbf{N}^{\prime}, \mathbf{N}^{\prime \prime}, \mathbf{N}^{\prime \prime \prime}\right.$ etc.) (open) $=\mathrm{L}_{\mathbf{0}}\left(\mathrm{L}_{\mathbf{0}}{ }^{\prime}, \mathbf{L}_{\mathbf{0}}{ }^{\prime \prime}, \mathbf{L}_{\mathbf{0}}{ }^{\prime \prime \prime}\right)$

$=$ (scars of) scale-like leaves (Figs. 8-17);

st; st'; st"

$=$ stipules (Figs. 2-17);

$\mathrm{v}\left(\mathrm{v}_{0}, \mathrm{v}_{1}, \mathrm{v}_{2}\right.$ etc.; $\mathrm{v}^{\prime}, \mathrm{v}^{\prime \prime}, \mathrm{v}^{\prime \prime \prime}$ etc. and combinations) (open)

$=1\left(1_{0}, 1_{1}, l_{2}\right.$ etc.; $1^{\prime}, 1^{\prime \prime}, l^{\prime \prime \prime}$ etc. and combinations $)$

$=$ (scars of) scale-like leaves (Figs. 8-17);

*

$=$ obliterated buds at the apex of inflorescences (IF etc.), central axes (CA, $\mathrm{CA}^{\prime}$ etc.) or lateral branchlets (LB etc.) (Figs. 4, 6-17). 


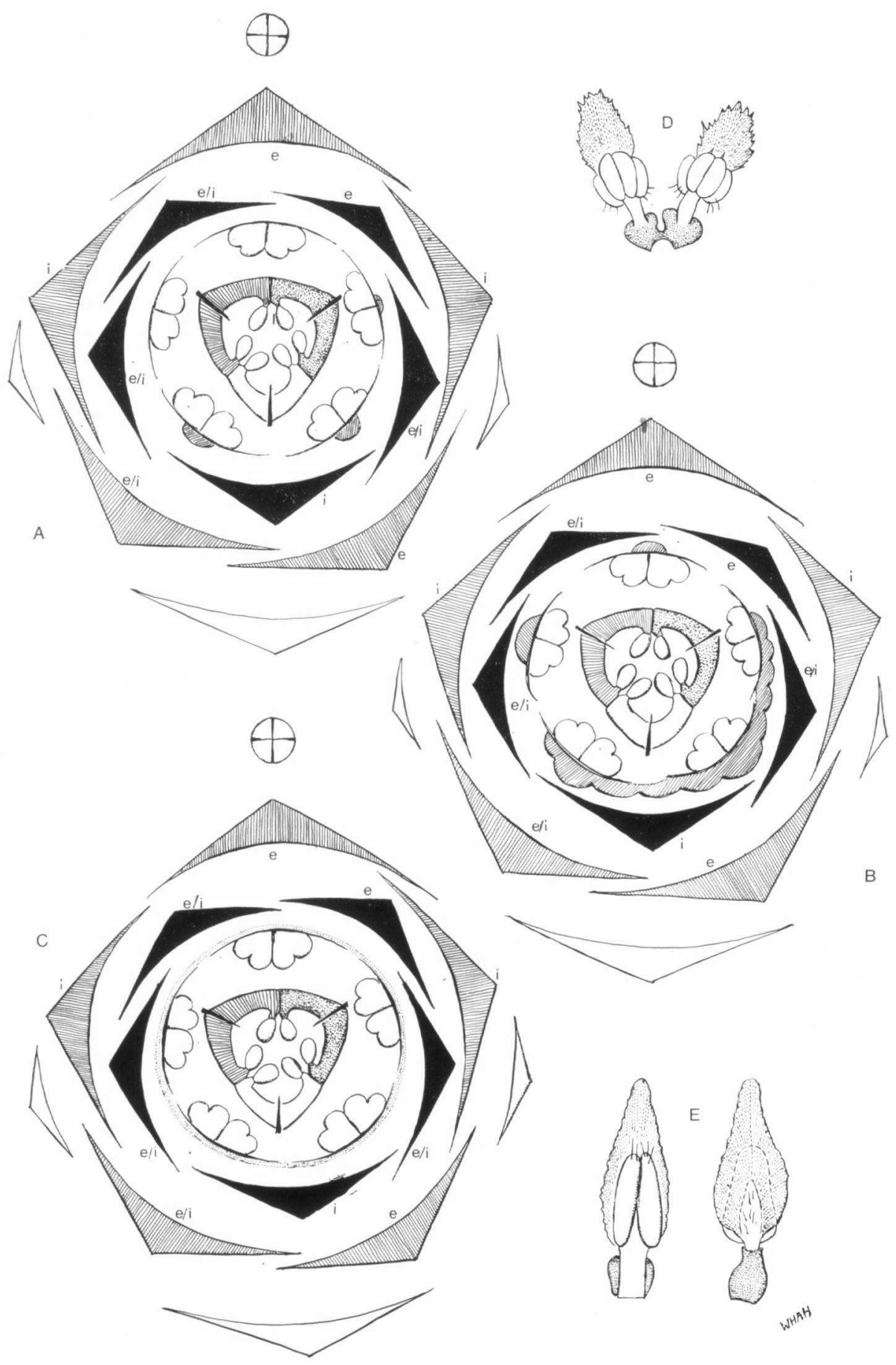

Fig. 1 (Legends see pages $374-376$ ) 


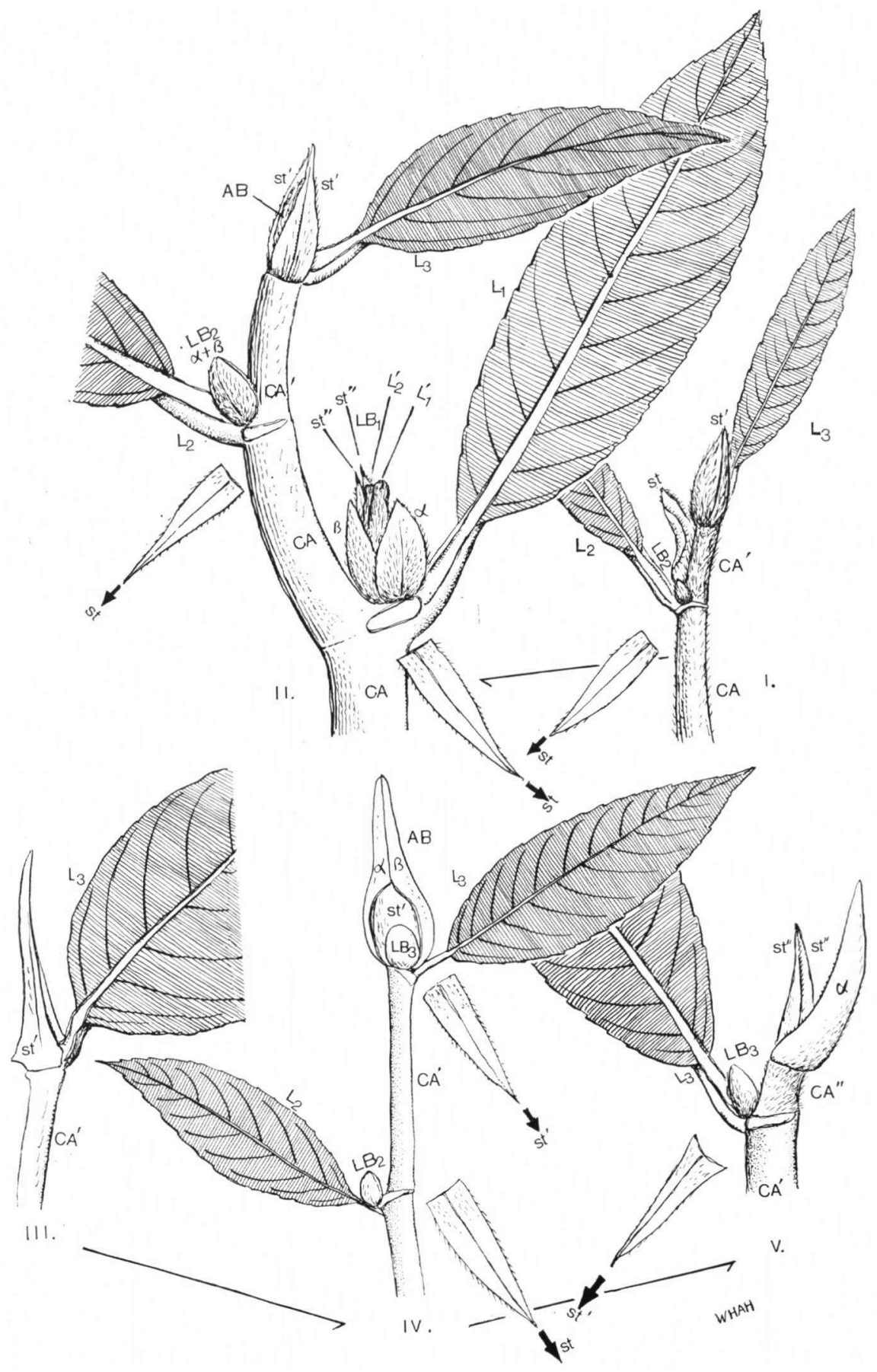

Fig. 2 


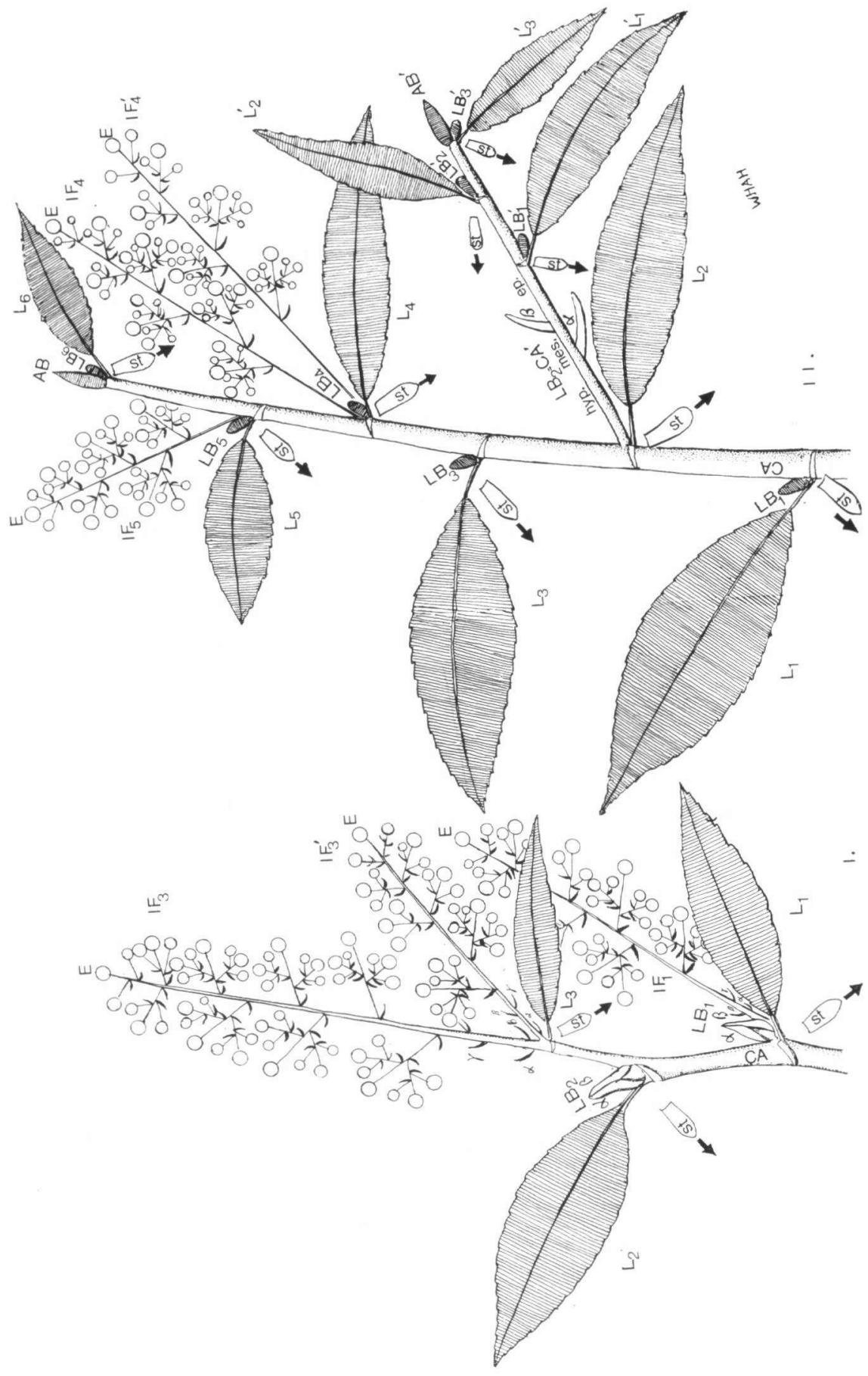




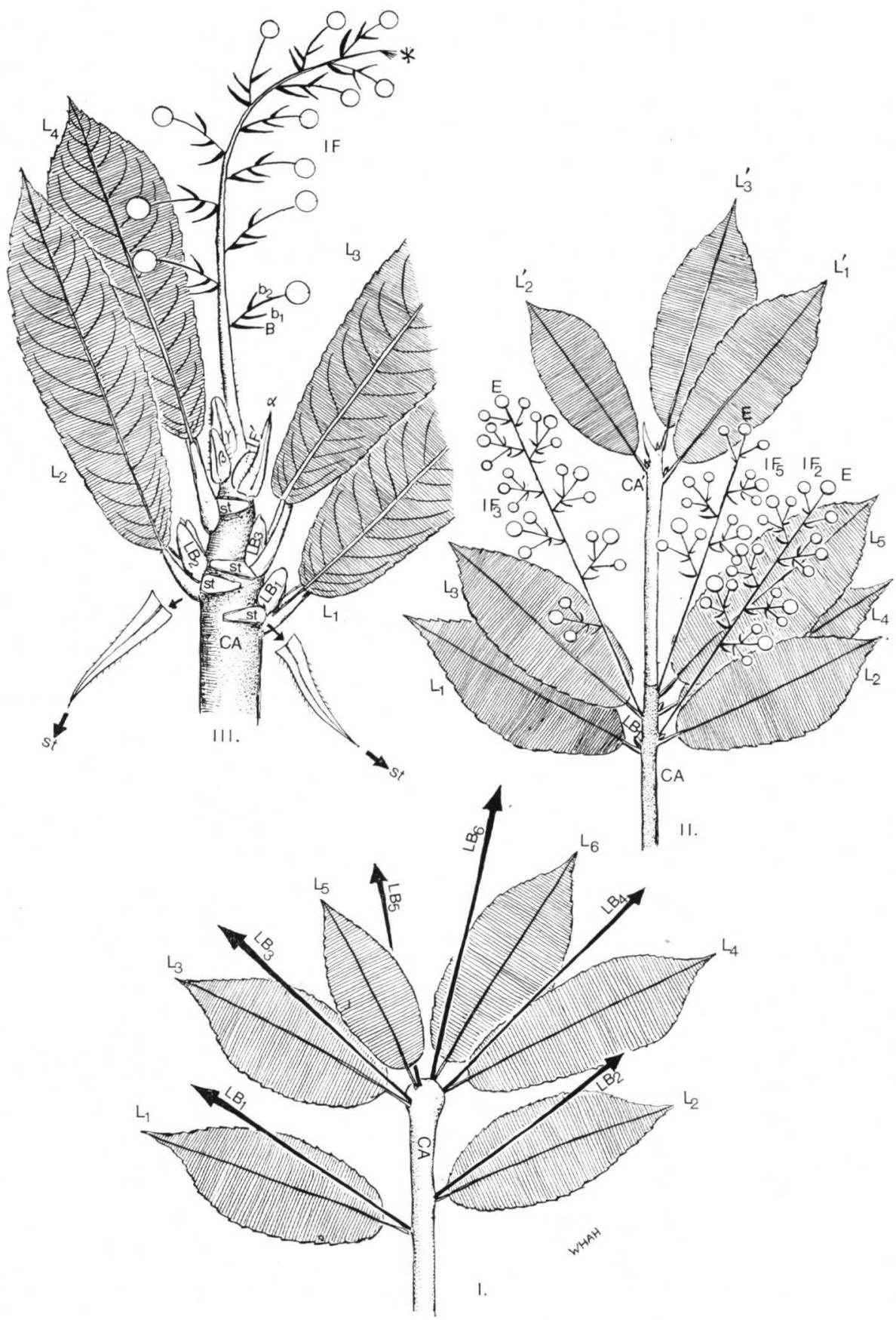

Fig* 4 
W. H. A. HEKKING

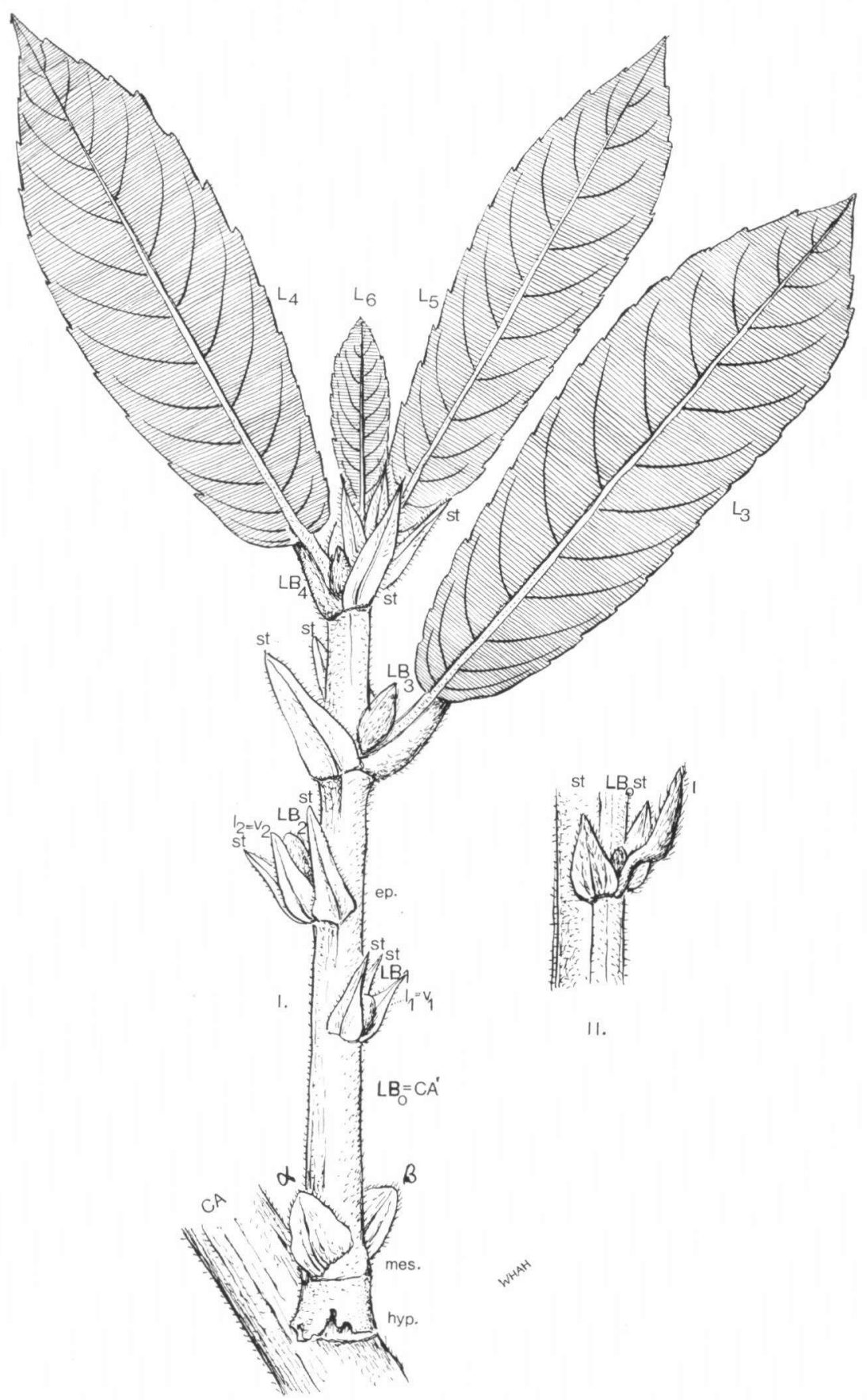

Fig. 5 


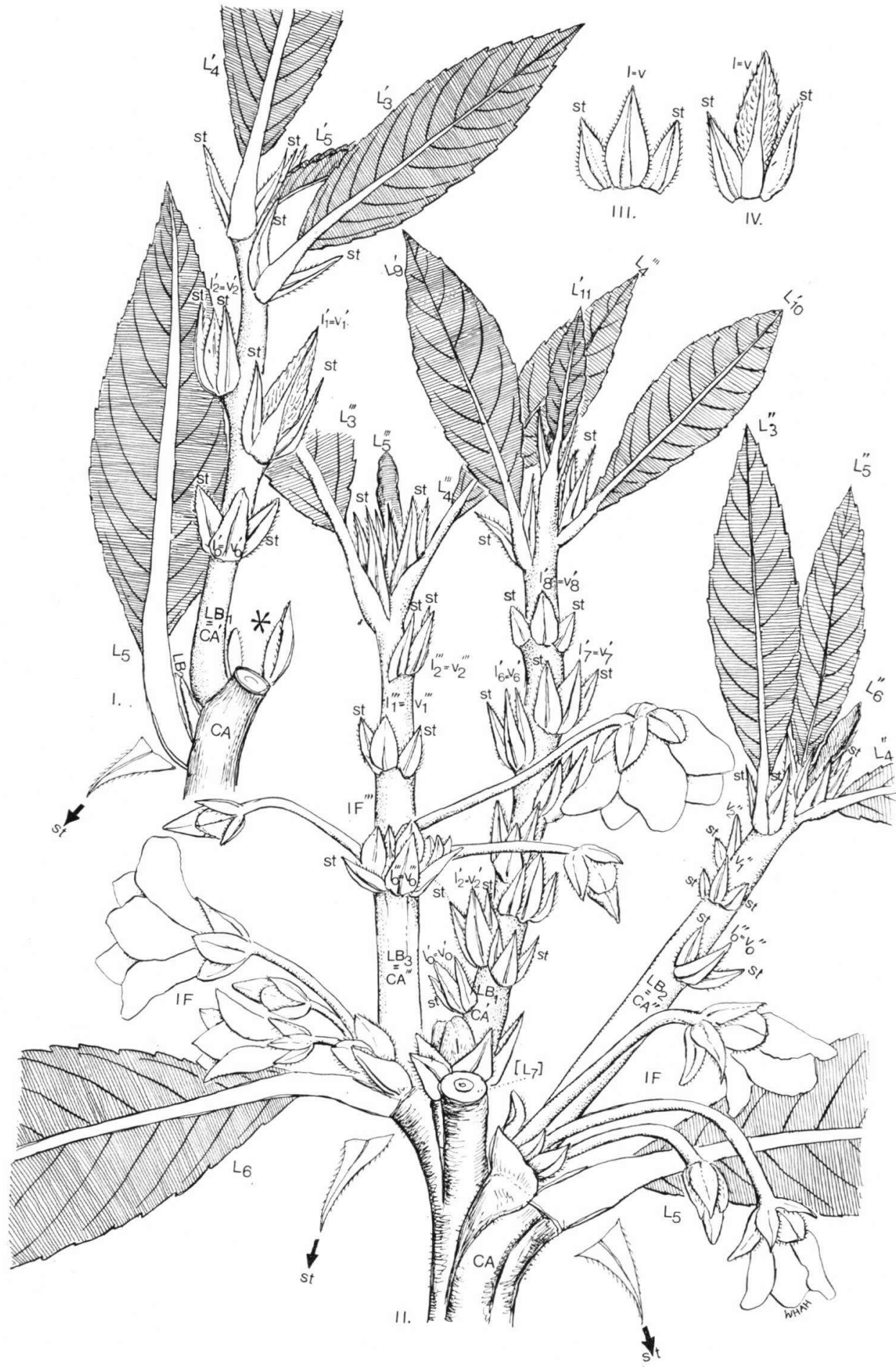

Fig. 6 


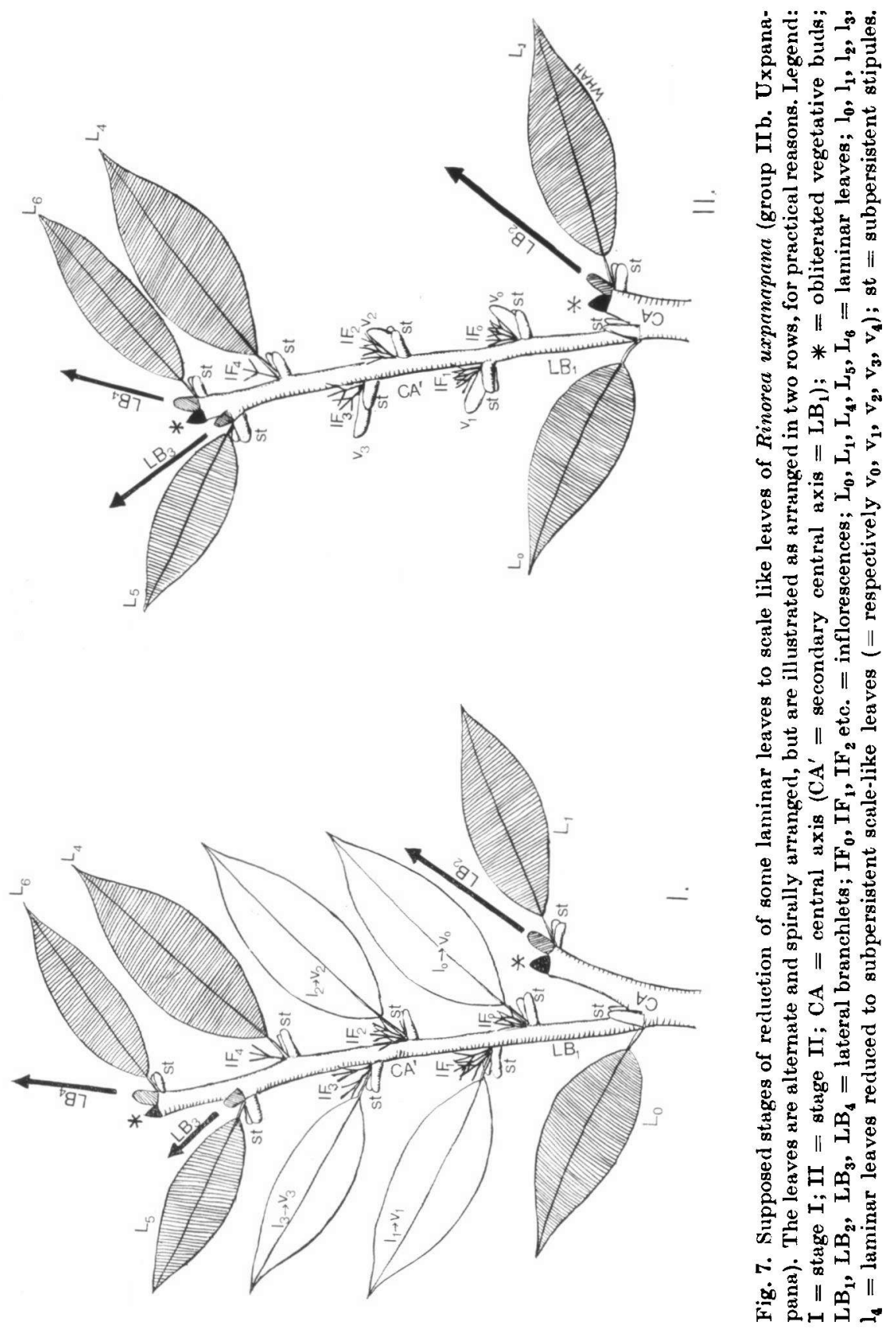




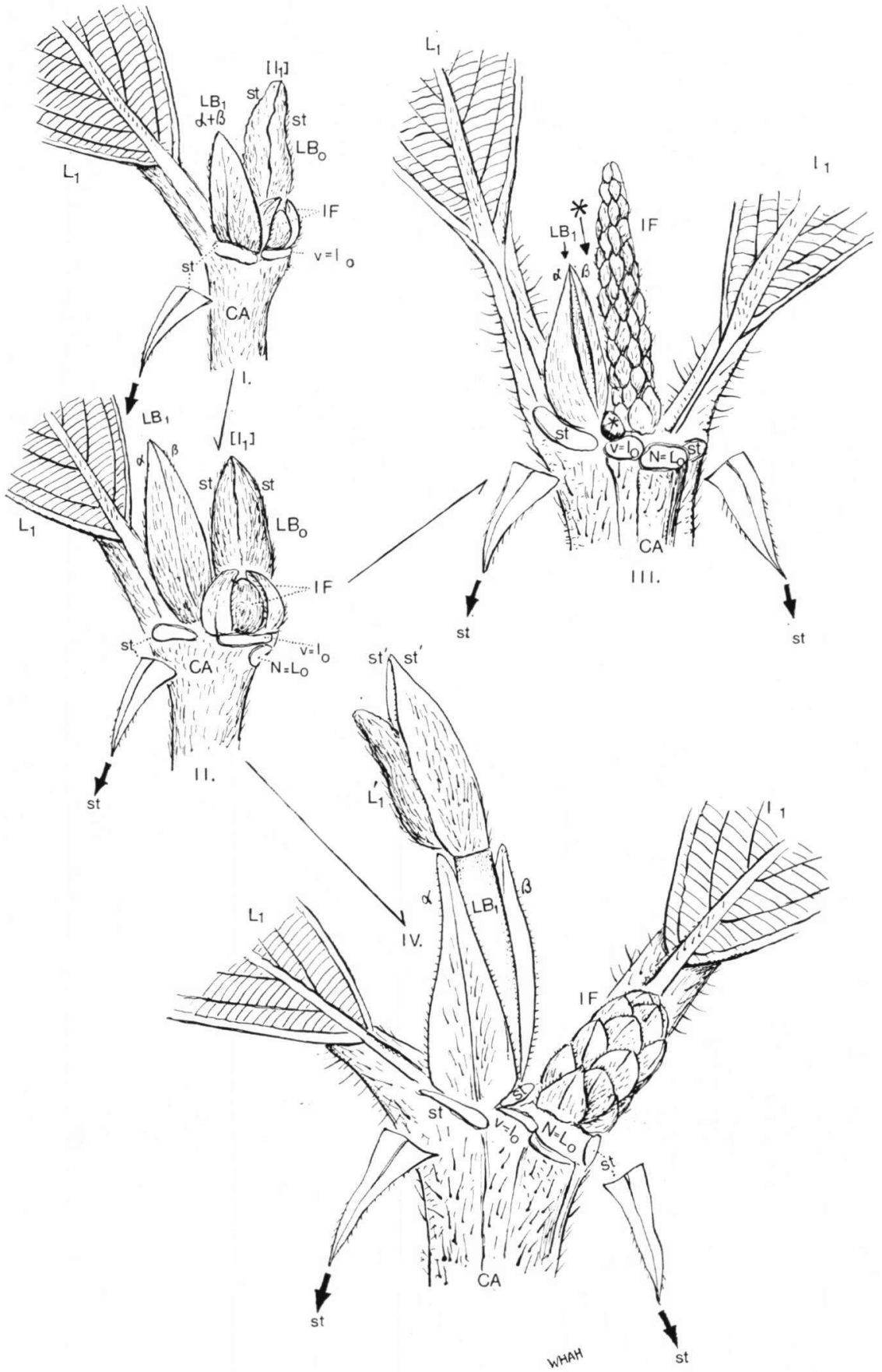

Fig. 8 


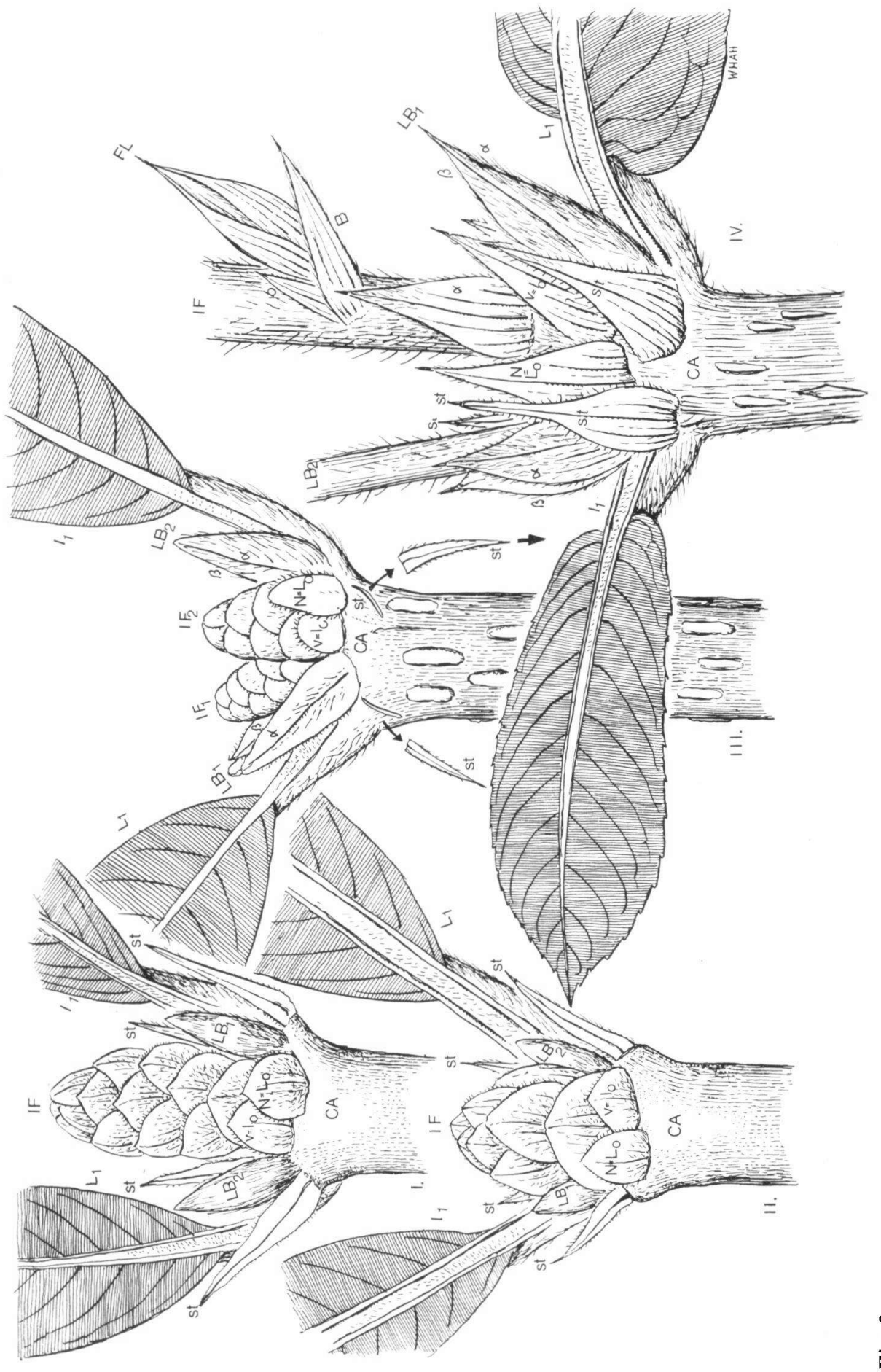




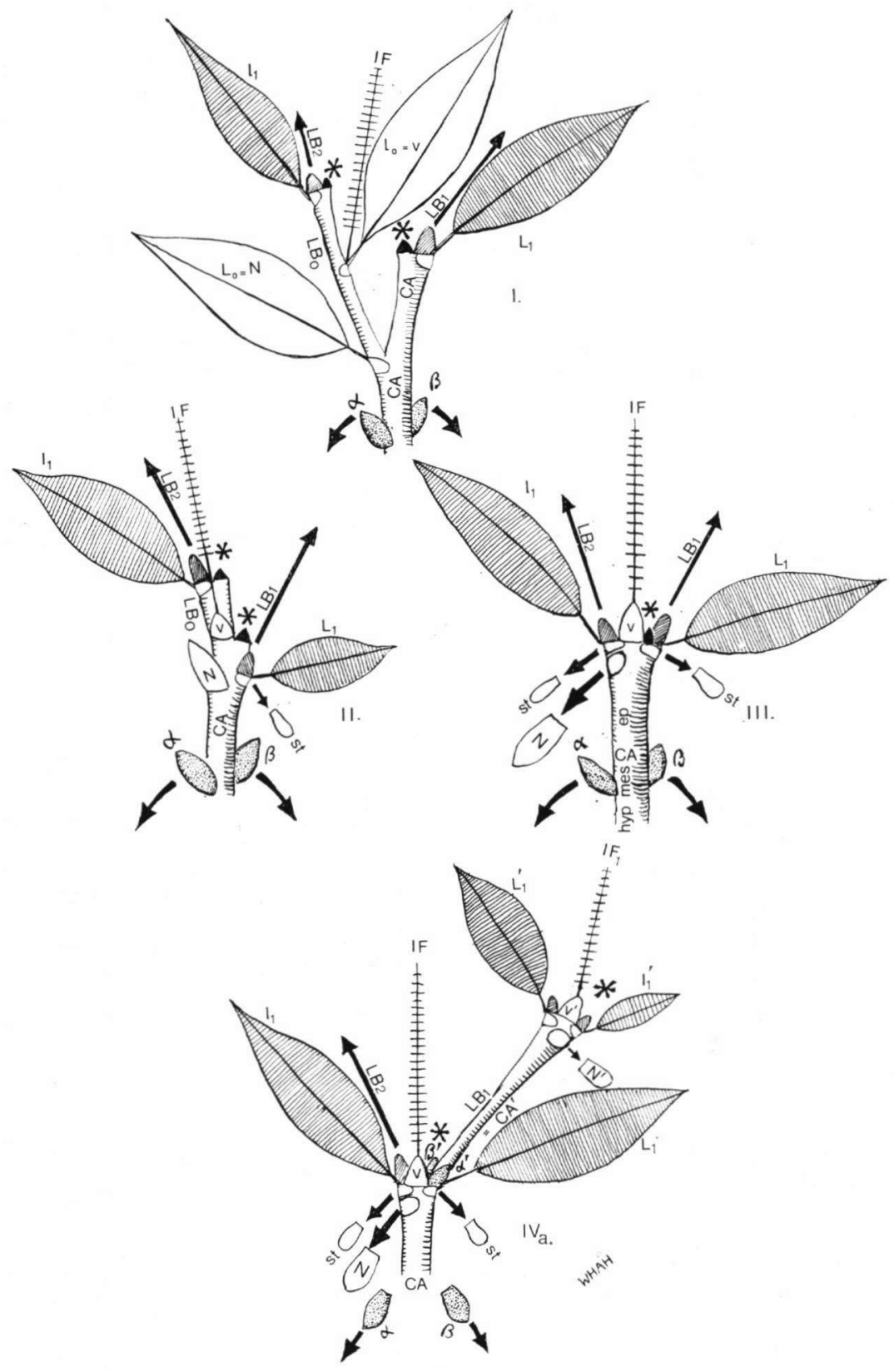

Fig. 10. Leaf arrangement and branching system in Rinorea group IIc. Pubiflora, characterized by 'apparently opposite' laminar leaves and by deciduous scale-like leaves at the base of the inflorescences; supposed stages of change from alternate to 'apparently' opposite phyllotaxy (see text). Legend: $\mathrm{I}, \mathrm{II}, \mathrm{III}$ and IV = stages I, II, III and IV. CA $=$ central axis (CA' $=$ secondary central axis, etc.). $*=$ obliterated vegetative buds; $\mathbf{L B}_{0}, \mathbf{L B}_{1}, \mathbf{L B}_{2}=$ lateral branchlets. IF, $\mathrm{IF}_{1}, \mathrm{IF}_{2}$ etc. $=$ inflorescences; $\mathrm{L}_{0}, \mathrm{~L}_{0}{ }^{\prime}$ etc. $\mathrm{l}_{0}, \mathrm{l}_{0}{ }^{\prime}$ etc. (open) $=$ originally laminar leaves reduced to scale-like (= respectively $N, N^{\prime}$ etc. $v, v^{\prime}$ etc.). $L_{1}, L_{1}{ }^{\prime}$ etc. and $l_{1}, l_{1}^{\prime}$ etc. (hatched) = leaves remaining laminar. st $=$ stipules; $\alpha$ and $\beta=$ prophylls; hyp. $=$ hypopodium; mes. $=$ mesopodium; ep. $=$ epipodium. 


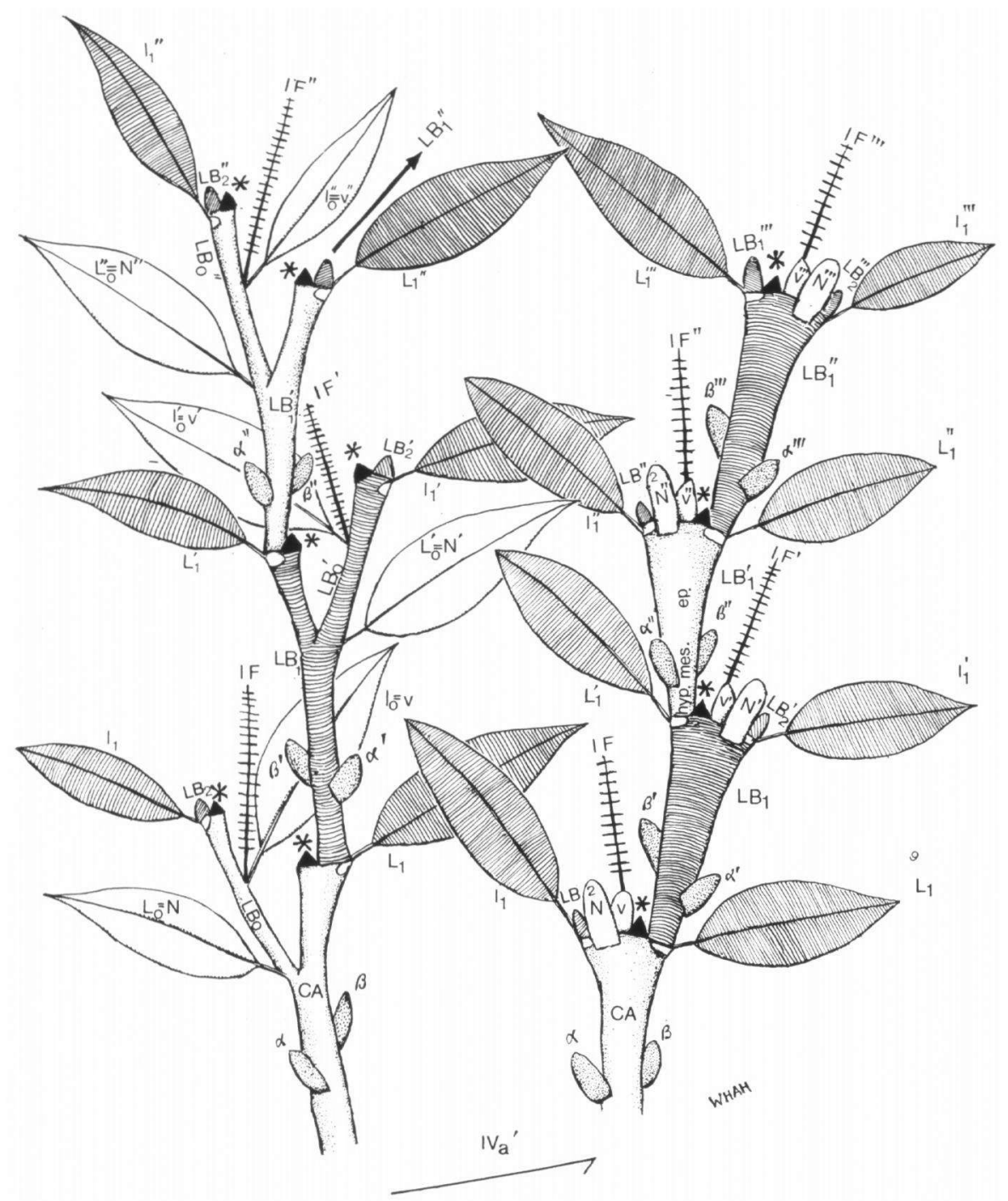

Fig. 11 (IV a'). Reconstruction of development to an elongated monochasial LB L $_{1}$ etc. branching system (as in Diagram IVa' of Fig. 17). Legend as in Fig. 10 and in General Legend. 


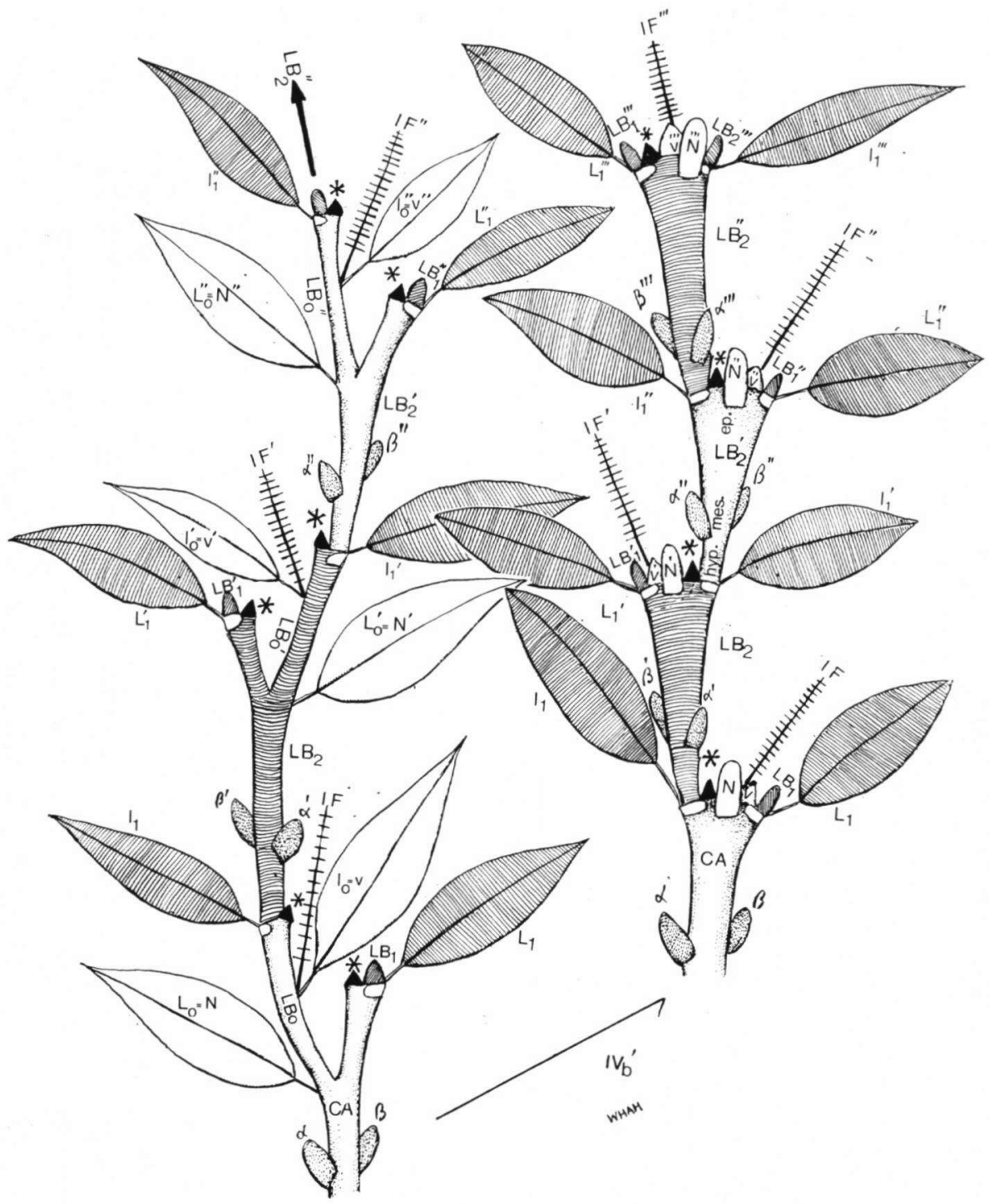

Fig. 12 (IV $\left.b^{\prime}\right)$. Reconstruction of development to an elongated monochasial $\mathrm{LB}_{\mathbf{2}}$ etc. branching system (as in Diagram IV b' of Fig. 17). Legend as in Fig. 10 and in General Legend. 


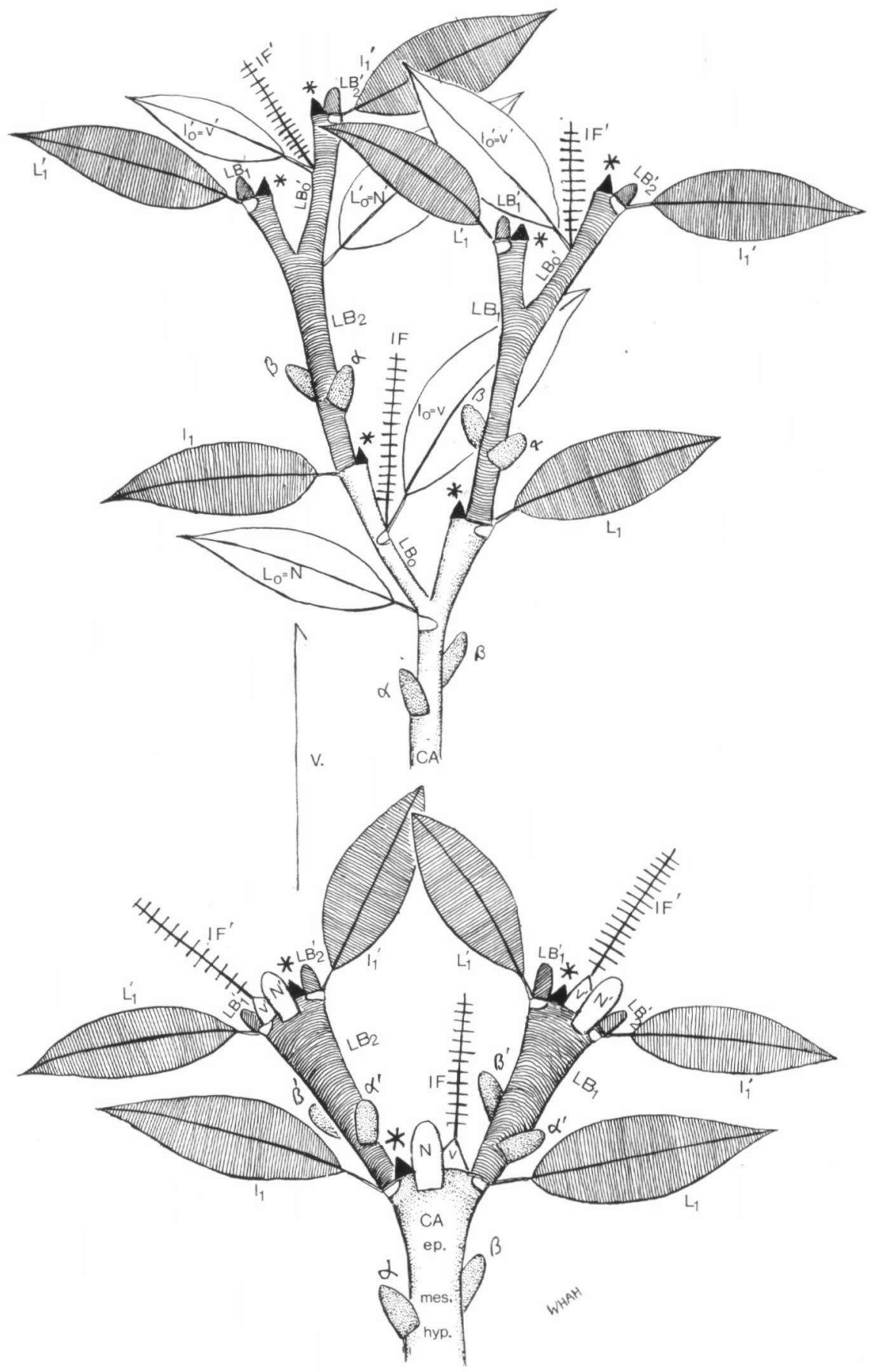

Fig. 13 (V). Reconstruction of development to a dichasial brunching system (as in Dirgram $\mathrm{V}$ in Fig. 16). Legend as in Fig. 10 and in General Legend. (Erratum: the upward arrow must be corrected to down.) 

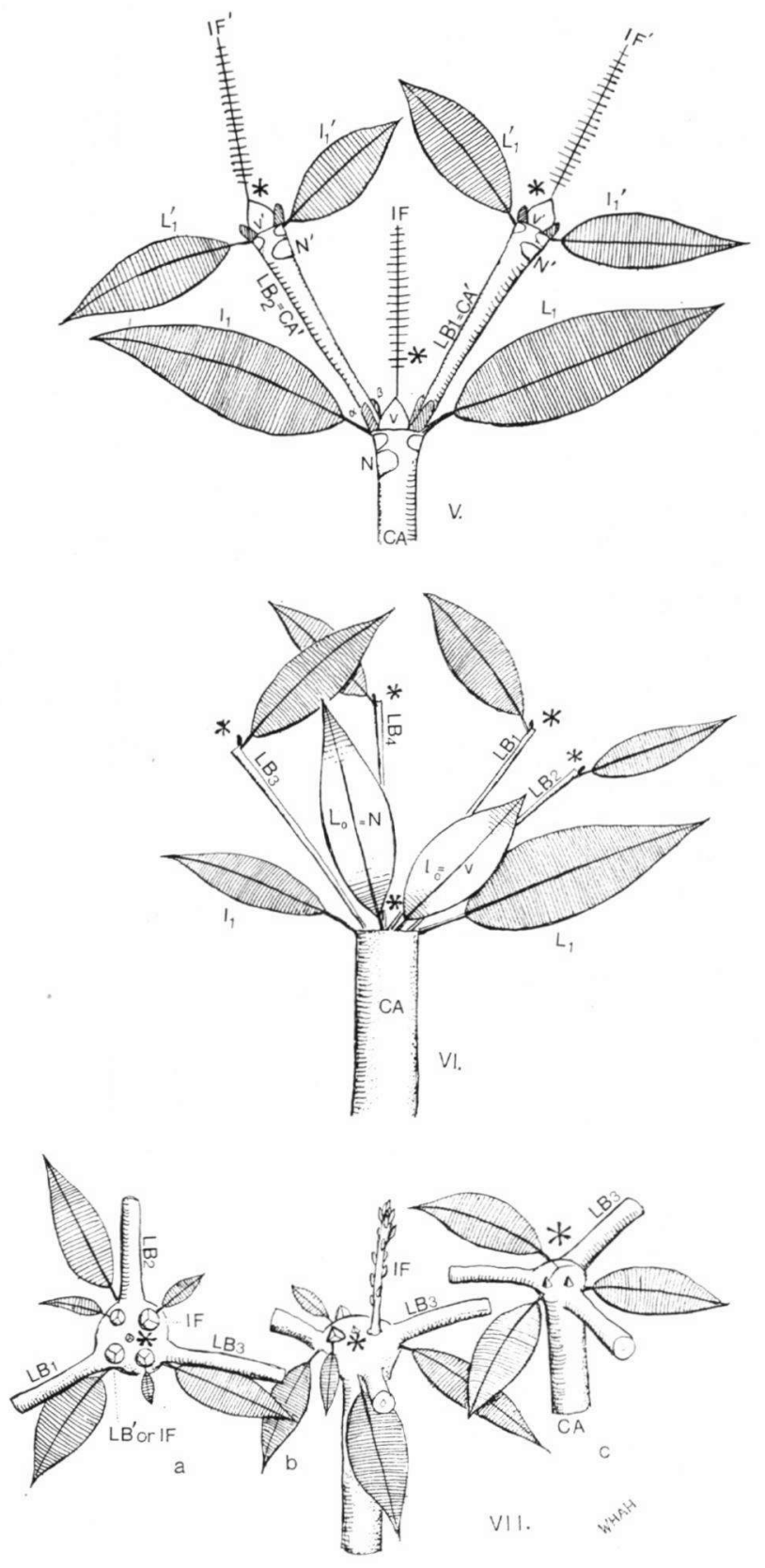

Fig. 14. Leaf arrangement and branching systems in Rinorea group IIc. Pubiflora. Stages V, VI and VII. Transition from a dichasial arrangement in $\mathrm{V}$ via a pleiochasial arrangement in VI to an instable plagiotropic arrangement in VII of a treelet of the Fagerlind model (VII after HaLLÉ, Ordeman \& Tomlinson 1978, modified). Legend as in Fig. 10 and in General Legend. 

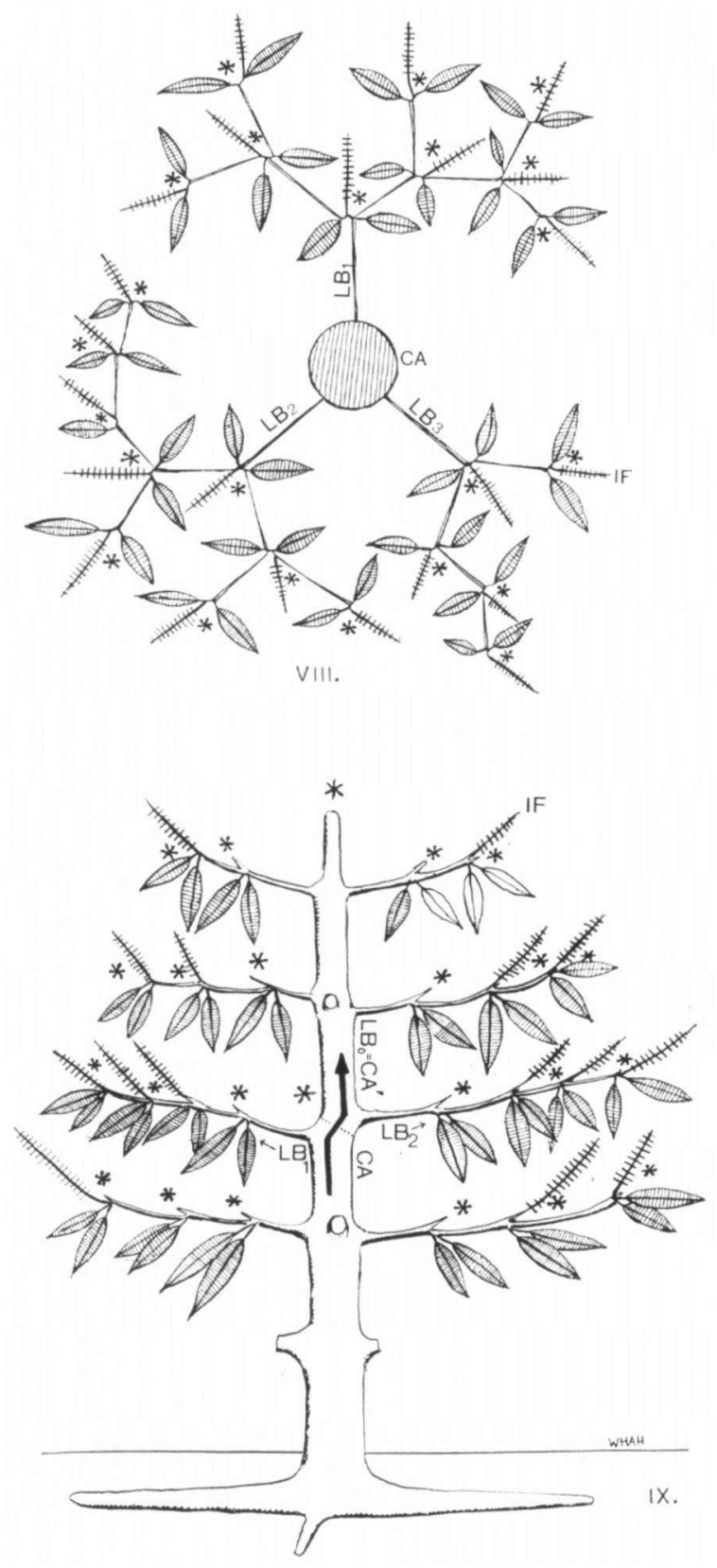

Fig. 15. Plagiotropic arrangement of mono- or dichasial branching systems in Fagerlind model of Rinorea group IIc. Pubiflora; VII. cross-section of the trunk, representing a vertical central axis $C A$ with horizontally arranged lateral branches $\mathrm{LB}_{1}, \mathbf{L B}_{2}$ and $\mathrm{LB}_{3}$; IX. longitudinal section of the trunk; the broken arrow delineated in the trunk indicates the spot of transition of a previous central axis CA (after obliteration of a former vegetutive bud $*$ ) to a secondary central axis $\mathbf{C A}^{\prime}$ (originating from a former lateral brunchlet $\mathrm{LB}_{0}$ ) etc. (after Otdeman (1974) and HaIL.́, OtdDEMaN \& Tombinson (1978), modified). Legend as in Fig. 10 and in Gen ral Legend. 

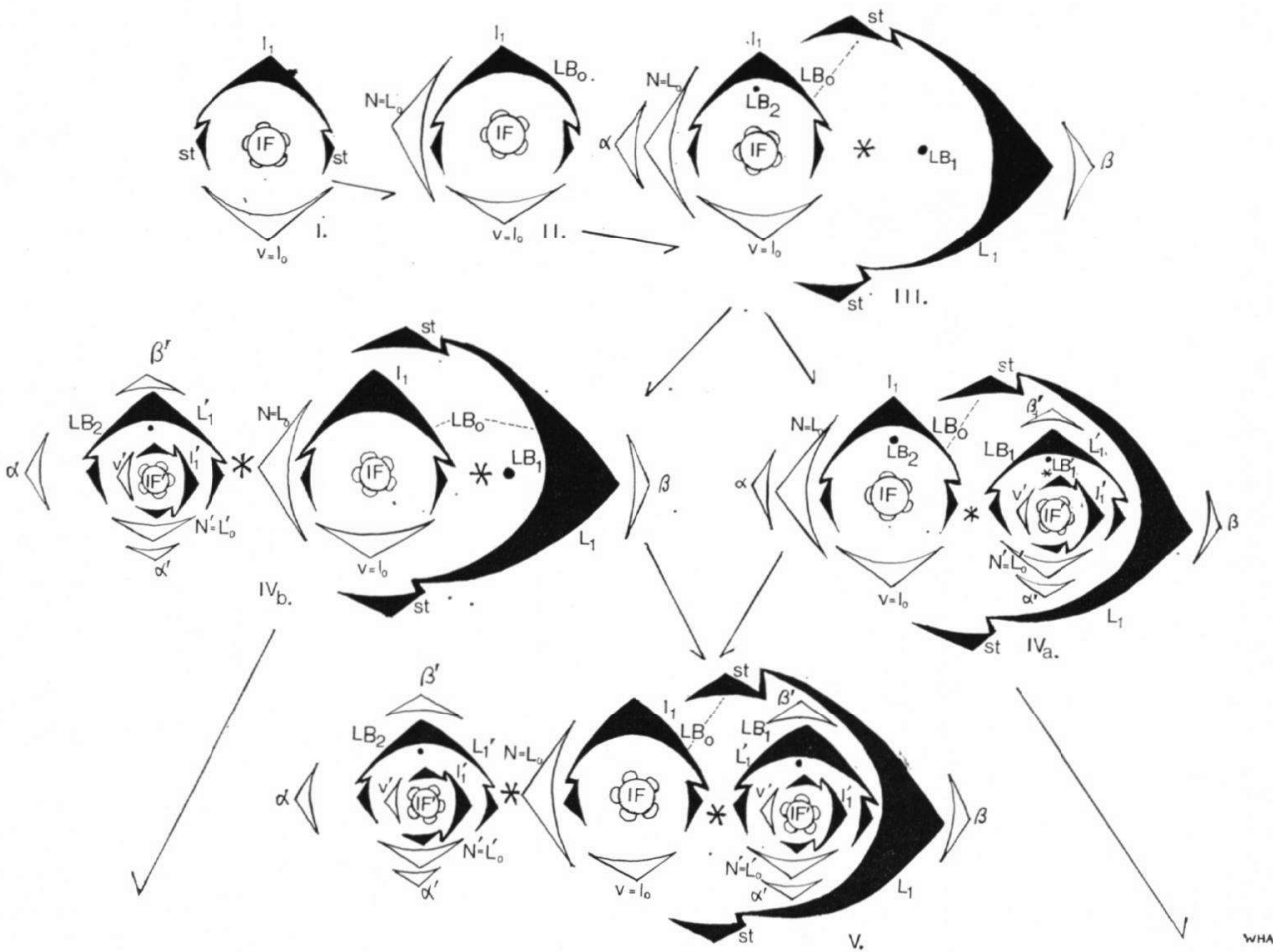

Fig. 16
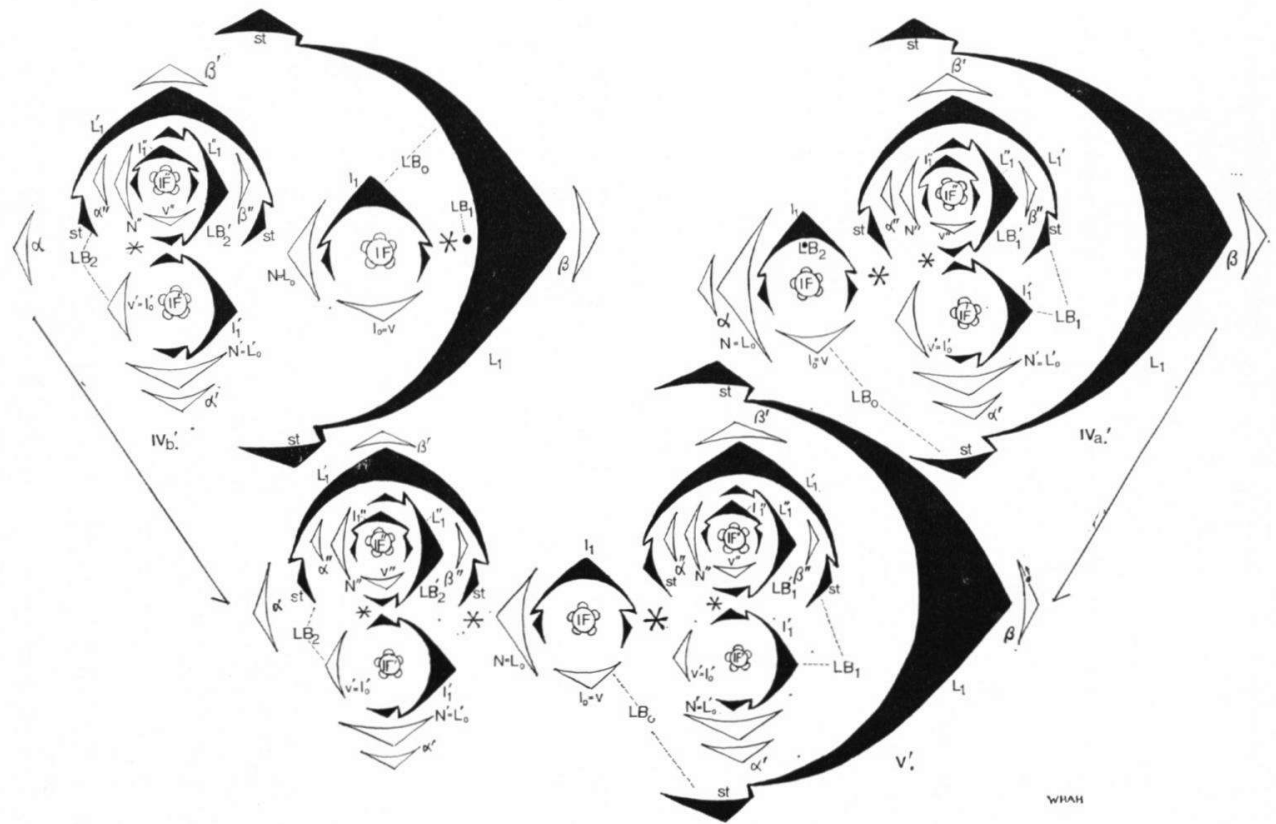

Fig. 17 
Legends to Figures $1 \longrightarrow 6,8,9,16,17$

Fig. 1. Floral diagrams of neotropical species of Rinorea: sepals quincuncial, petals apotact, filaments and dorsal glands free or fused to a tube dorsal connective scales laminar; gynoecium 3-merous. $\theta=$ outer sepal or petal (= exterior); $i=$ inner sepal or petal ( $=$ interior); i/e or e/i $=$ one sepal or petal in between, with one margin outside (= exterior), the other one inside (= interior). There are three variations in the flower structure of Rinorea: A. filanenta and dorsal glands free; dorsul glands of anterior filaments usually more developed than those of the posterior ones (which may be also wanting). B. only the dorsal glands of the anterior filaments fused with each other. C. all filaments and usually also all dorsul glands fused to a tube.

There are two variations in the structure of the connective scales: $D$. connective scales only apical (supergroup I: Apiculata); E. connective scales apical as well as lateral (supergroup II: Rinorea).

Fig. 2. Analyses of growth processes in apical (= distal) branchlets in Rinoren guianensis AuBLET (group IIa. Rinorea), a species with an alternate leaf arrangement (reconstructions from herbarium specimens).

I-II. first series of growth processes in apical (= distal) branchlets:

I. Duarte 5472; II. Ducke \& Kuhlmann 137598.

III-IV-V. second series (idem):

III. Prance et al. P-25583; IV. Oldeman B-813; V. Prance et al. 8955.

$\mathbf{C A}=$ central axis of older generation; $\mathbf{C A}^{\prime}$ and $\mathbf{C A}^{\prime \prime}=$ central axes of younger generations; $\mathrm{L}_{1}$ and $\mathrm{L}_{2}=$ older laminar leaves accompanied by stipules (=st) and subtending lateral buds $\mathrm{LB}_{1}$ and $\mathrm{LB}_{2} ; \mathrm{L}_{3}=$ younger laminar leaf uccompanied by stipules (st'); $\mathrm{AB}=$ apical vegetative bud; $\alpha$ and $\beta=$ prophylls ; $\mathbf{L B}_{3}=$ lateral bud subtended by laminar leaf $\mathrm{L}_{3} ; \mathrm{L}_{1}^{\prime}$ and $\mathrm{L}_{2}^{\prime}=$ juvenile laminar leaves of $L B_{1}$, accompanied by their stipules (=st").

Fig. 3. Arrangements of leaves, lateral branchlets and inflorescences in Rinorea guianensis AUBLET (group IIa. Rinorea), characterized by having alternate leaves.

I. Vieira et al. 598.

II. schematic drawing, destillated from various herbarium specimens.

A. central axis $\mathbf{C A}$ (in $I$ and II): $\mathbf{A B}=$ apical bud; $\mathbf{L}_{1-6}=$ laminar leaves; st $=$ stipules; $\mathbf{L B}_{1-6}$ $=$ lateral buds becoming lateral branchlets; $\mathrm{IF}_{\mathbf{1 - 4}}=$ inflorescences; IF' $_{3-4}=$ associrted inflorescences; $\mathrm{E}=$ terminal flower; $\alpha, \beta$ and $\gamma=$ prophylls in lateral buds and in inflorescence $\mathrm{IF}_{\mathbf{3}}$.

B. lateral branchlet $\mathrm{LB}_{2}$, becoming a secondary central axis $\mathrm{CA}^{\prime}$ (in II), subtended by laminar leaf $\mathrm{L}_{2}$ :

$\mathbf{A B}^{\prime}=$ secondary apical bud; $\mathrm{L}_{1-\mathrm{s}}^{\prime}=$ laminar leaves; st = stipules; $\mathbf{L B}_{1-3}^{\prime}=$ secondary lateral buds; hyp. = hypopodium, part of $\mathbf{C A}^{\prime}$ below the propyhlls $\alpha$ and $\beta$; mes. = mesopodium, part of $\mathrm{CA}^{\prime}$ between the prophylls $\alpha$ and $\beta$; ep. $=$ epipodium, purt of $\mathbf{C A}^{\prime}$ above the prophylls $\alpha$ and $\beta$.

Fig. 4. Nodular structures with congested arrangement of leaves, inflorescences and laterul branchlets in species with ulternate leaves.

A. supergroup I: A piculata.

I. occasionally in Rinorea crenata Blake: PitTIER \& Tonduz 9183.

B. supergroup II: Rinorea; Group II a. Rinorea.

II. Rinorea ramiziana Grazrov ex Hekking: Brade, Altamtro \& Apparicio 18087

III. Rinorea laevigata (Solander ex GINGINS) HekkING (syn. R. physiphora, ,BaILLON“4): Soner \& MARX 1187

$\mathbf{C A}=$ central axis $; \mathbf{C A}^{\prime}=$ secondary central axis; $\mathbf{L}_{1-6}=$ laminar leaves of $\mathbf{C A} ; \mathbf{L}_{1-3}^{\prime}=$ lamin $\curlywedge \mathbf{r}$ leaves of $\mathbf{C A}^{\prime}$; st $=$ stipules; $\mathbf{L B}_{1-6}=$ lateral buds or laterul branchlets; IF = 'apical' infl srescence (in III); IF' $^{\prime}=$ 'associate' inflorescence in bud (in III); IF $_{2-5}=$ lateral inflorescenc 39 (in II); $\alpha$ and $\beta=$ prophylls of inflorescence IF (in III); $B=$ bract at the base of a 'pedicel'; $b_{1}$ and $b_{2}=$ bractlets just below the articulation of the 'pedicel'; $E=$ terminal flower in inflorescences in II; $*$ = obliterated apical part in inflorescence IF (in III). 
Fig. 5. Arrangement of laminar and occasional scale-like leaves in Rinorea laevigata (SoLANDER

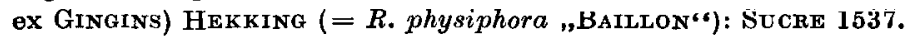

I. habit: $\mathbf{C A}=$ central axis; $\mathbf{L B}_{0}=$ lateral branchlet, becoming a secondary central axis $\mathbf{C A}^{\prime}$; $\mathbf{L}_{3-6}=$ laminar leaves, congested in the apical part; $1_{1-2}=v_{1-2}$, scale-like leaves arranged in the basal part; st = stipules; $L B_{1-4}=$ lateral buds, subtended by both kinds of leaves; $\alpha$ and $\beta=$ prophylls of $\mathrm{LB}_{0}=\mathrm{CA}^{\prime}$; hyp. = hypopodium; mes. = mesopodium; ep. = epipodium.

II. detail of a differentiated scale-like leaf:

$\mathbf{L B}_{0}=$ lateral branchlet; $l=$ scale-like leaf differentiated into petiole and lamina; st = stipules.

Fig. 6. Arrangement of alternate laminar and scule-like leaves in Rinorea uxpanapana T. WENDT (group IIb. Uxpanapana), type-specimen: WeNDT et al. 3907.

I-II. habit: $\mathrm{CA}=$ central axis; $\mathrm{LB}_{\mathrm{I}-3}=$ lateral branchlets, becoming to secondary central axes: $\mathrm{CA}^{\prime}, \mathrm{CA}^{\prime \prime}, \mathrm{CA}^{\prime \prime \prime} ; \mathrm{L}_{1-10}, \mathrm{~L}^{\prime}, \mathrm{L}^{\prime \prime}$ and $\mathrm{L}^{\prime \prime \prime}$ and combinations = laminar leaves; $\left[\mathrm{L}_{7}\right]=$ laminar leaf broken off; $\mathrm{l}_{0-8}, \mathrm{l}^{\prime}, \mathrm{l}^{\prime \prime}$ and $\mathrm{l}^{\prime \prime \prime}$ and combinations $\left(=\mathrm{v}_{0-8}, \mathrm{v}^{\prime}, \mathrm{v}^{\prime \prime}\right.$ and $\mathrm{v}^{\prime \prime \prime}$ and combinations) $=$ scale-like leaves; $\mathrm{st}=$ stipules; IF and $\mathrm{IF}^{\prime \prime \prime}=$ cymose inflorescences; $*=$ obliterated apical bud or lateral branchlet broken off.

III-IV. scale-like leaves in detail $(1=v)$ with accompanying stipules (= st); III. scale-like leaf undifferentiated; IV. scale-like leaf differentiated into a lamina and a petiole.

Fig. 8. Analyses of development in apical (= distal) branchlets in Rinorea racemosa (MARTIUs) Kuntze (group II c. Pubiflora), having an apparently opposite leaf arrangement.

I-IV. series of development reconstructed from herbarium specimens:

I \& IV. Gentry 13203: II. Hill, Anderson \& Anderson 1676; III. Amaral, Cid et al. 512. $\mathbf{C A}=$ central axis; $L_{1}=$ laminar leaf of central axis $\mathbf{C A} ; l_{1}=$ laminar leaf of reduced lateral branchlet $\mathbf{L B}_{0} ;\left[l_{1}\right]=$ idem, but enclosed by stipules (= st) of laminar leaf $1_{1}$; st = stipules of laminar leaves $L_{1}$ and $l_{1} ; N=L_{0}$, scar of scale-like leaf of central axis $C A ; v=l_{0}$, scar of scale-like leaf of reduced lateral branchlet $\mathrm{LB}_{0}$; IF $=$ inflorescence, belonging to reduced lateral branchlet $\mathbf{L B}_{0} ; \alpha$ and $\beta=$ prophylls of lateral bud or lateral branchlet $\mathbf{L B}_{1}$, subtended by laminar leaf $\mathrm{L}_{1} ; \mathrm{L}_{1}^{\prime}=$ young laminar leaf of lateral branchlet $\mathrm{LB}_{1}$, accompanied by two stipules $\left(=\right.$ st $\left.^{\prime}\right) ; *=$ obliterated apical vegetative bud of central ax is $\mathbf{C A}$ (in III).

Fig. 9. Analyses of development in apical (= distal) branchlets from herbarium specimens of Rinorea species (group IIc. Pubiflora) having an apparently opposite leaf arrangement.

I and II. R. flavescens Aublet: Amaral, Cid et al. 86;

III. R. riana KUNTZE: KNAPP \& Mallet 2849;

IV. R. sylvatica (SEEMANN) KUNTzE: LIESNER et al. 15040.

CA = central axis; $\mathrm{L}_{1}=$ laminar leaf of central axis CA; $1_{1}=$ laminar leaf of reduced lateral branchlet $\mathrm{LB}_{0}$; st $=$ stipules of laminar leaves $\mathrm{L}_{1}$ and $\mathrm{I}_{1} ; \mathrm{N}=\mathrm{L}_{0}$, scale-like leaf of central axis CA; $\mathbf{v}=\mathrm{l}_{0}$, scale-like leaf of reduced lateral branchlet $\mathrm{LB}_{0} ; \mathrm{IF}, \mathrm{IF}_{1}, \mathrm{IF}_{2}=$ inflorescences; $B=$ bract at the base of the 'pedicels'; $b=$ braclet, just below the articulation of the 'pedicel'; FL = flower (bud); $\mathbf{L B}_{1}$ and $\mathbf{L B}_{2}=$ lateral buds or lateral branchlets; $\alpha$ and $\beta=$ prophylls of $\mathbf{L B}_{1}, \mathbf{L B}_{2}$ and IF. Leaf arrangement: $l_{1}\left(L_{0}\right) ; N=L_{0}(C A) ; v=l_{0}\left(L_{0}\right) ; L_{1}(C A)$; "clockwise" in I and III; "anti-clockwise" in II and IV.

Fig. 16. Development to a monochasial branching system (I, II, III, IV a, IV b) and a simple dichasial branching system (V) in Rinorea group IIc. Pubiflora, expressed in a series of diagrams (see text); Diagram III represents a central axis CA as in Fig. 10 (III) with an apparently terminal inflorescence IF; Diagram IVa represents a starting monochasial $L_{1}$ branching system as in Fig. 10 (IV a); Diagram IV b represents a starting monochasial LB 2 branching system; Diagram V represents a starting dichasial branching system by combination of Diagrams IVa and IVb (cf. Figs. 13 (V) and 14 (V)). Diagrams I, II, II, IV a and IV b differ in some details of those in Fig. 434 of TroLl (1969). Legend as in Fig. 10 and General Legend. 
Fig. 17. Development to an elongated monochasial branching systems ( $\mathrm{IVa}^{\prime}$ according to $\mathrm{LB}_{1}$ etc. branching system as in Fig. 11 (IV $a^{\prime}$ ); IV b according to $\mathrm{LB}_{2}$ etc. branching system as in Fig. 12 $\left(I V b^{\prime}\right)$ ) and a more complicated dichasial branching system $\left(V^{\prime}\right)$ by combination of Stages IV a' and $I V b^{\prime}$. Legend as in Fig. 10 and General Legend.

\section{Literature}

Eichler, A. W. (1870): Ueber die Blattstellungen einiger Alsodeien. Flora (Regensburg) 26: $401-409$, tab. 4.

Hatlé, F., R. A. A. Oldeman \& P. B. Tomlinson (1978): Conohoria. In: Tropical Trees and Forests: 8, 168-173. Figs. 36, 38. Berlin, Heidelberg, New York.

Hekking, W. H. A. (1988): Violaceae, Subfumily Violoideae, Tribe Rinoreeae, Subtribe Rinoreinae, Part I - Rinorea and Rinoreocarpus. Monograph 46, Flora Neotropica: 1-208, Figs. 1-63. New York.

Oldeman, R. A. A. (1974): Conohoria. In: L'Architecture de la Forêt Guyanaise: 25-26. Figs. 11-12. ORSTOM-Paris.

Trout, $W$. (1969): 6. Violaceae in $\$ 4$. Reduktionserscheinungen innerhalb der Bereicherungazone. In: Die Infloreszenzen 2 (1): 525-529. Abb. 433-435, Jena.

Received March 3, 1987

Author's address: W. H. A. Hekrivg, Institute of Systematic Botany, Transitorium II, Heidelberglıan 2, de Uithof, Utrecht $3584 \mathrm{CS}$, the Netherlands. 